Postprint: Tijskens A., Janssen H., Roels S., 2020. The impact of a reduced training subspace on the prediction accuracy of neural networks for hygrothermal predictions. Journal of Building Simulation Performance 2021, 14(1)

\title{
The impact of a reduced training subspace on the prediction accuracy of neural networks for hygrothermal predictions
}

\author{
Astrid Tijskens ${ }^{a, *}$, Hans Janssen $^{a}$, Staf Roels ${ }^{a}$ \\ ${ }^{a}$ KU Leuven, Department of Civil Engineering, Building Physics Section, Kasteelpark Arenberg 40 Bus 2447,3001 Heverlee, Belgium \\ * Corresponding author. Tel.: +32 16 323808; fax: +32 163 21980; E-mail address: astrid.tijskens@kuleuven.be; ORCID ID: https://orcid.org/0000- \\ 0003-4568-7769
}

\begin{abstract}
Performing a probabilistic assessment of a building component can easily become computationally inhibitive.

To solve this issue, the hygrothermal model can be replaced by a metamodel, which mimics the original model with a strongly reduced calculation time. In this paper, convolutional neural networks are used to predict hygrothermal performance. Because neural networks do not extrapolate well outside their training subspace, it is important to select the training data wisely so that the network can be used to predict for a wide variety of cases, while keeping training time as low as possible. The impact of a reduced training subspace is investigated by training a network on a limited number of wall types or exterior climates and evaluate its prediction accuracy for different wall geometries or other climates. The results showed that is indeed possible to train on a well-considered reduced subspace, while maintaining high accuracy, though it does not necessarily save training time.
\end{abstract}

\section{KEYWORDS}

Metamodelling; Convolutional neural networks, Time series modelling; Probabilistic assessment; Hygrothermal assessment

\section{Introduction}

The need to post-insulate existing buildings has increased the demand for hygrothermal simulations of building components to evaluate the benefits and risks of possible insulation measures. Such an evaluation includes many uncertainties, such as the exterior and interior climate, the material properties, or even the configuration geometry. Unlike a deterministic assessment, a probabilistic approach enables taking into 
Postprint: Tijskens A., Janssen H., Roels S., 2020. The impact of a reduced training subspace on the prediction accuracy of neural networks for hygrothermal predictions. Journal of Building Simulation Performance 2021, 14(1)

https://doi.org/10.1080/19401493.2020.1832148

account these uncertainties [1-6] and thus allows a more reliable assessment of the hygrothermal performance and the potential moisture damages. Often the Monte Carlo approach [7] is used, where the uncertain input parameters' distributions are sampled several times and a deterministic simulation is executed for each sampled parameter combination. However, this methodology easily requires thousands of simulations, and thus may become computationally inhibitive. By replacing the original hygrothermal model by a much simpler and faster metamodel, mimicking the original model, the calculation time can be reduced significantly. In the specific context of hygrothermal performance prediction, dynamic metamodels have a powerful advantage over static metamodels. Dynamic metamodels aim to predict time series (temperature, relative humidity, moisture content, ...), and thus provide a more flexible approach, whereas static metamodels are developed for a specific single-valued performance indicator [8-10] (e.g. the total heat loss or the maximal mould growth index). Predicting the hygrothermal time series allows post-processing by any desired damage prediction model (e.g. the VTT mould growth index), and furthermore provides information over the whole evaluation period. Using a dynamic metamodel to replace hygrothermal simulations is, tot the authors' knowledge, novel to the field of building physics. In light of the increasing application of probabilistic assessments for which standard HAM-models are often too time-consuming, this approach could be significant added value to the current state of the art. Nonetheless, developing a dynamic metamodel is also more challenging, as the metamodel must be able to capture the complex and timedependent patterns between input and output time series, and not all metamodelling strategies are suited for time series prediction.

In previous studies [11,12], the authors demonstrated that convolutional neural networks are well suited to reproduce the dynamic hygrothermal response of a building component and could reduce simulation time significantly. In [12], a neural network is developed to predict the hygrothermal behaviour of a massive masonry wall, in a probabilistic framework considering uncertainties related to e.g. interior and exterior climate, wall thickness and brick type. The network was trained on a small dataset obtained by sampling the 
Postprint: Tijskens A., Janssen H., Roels S., 2020. The impact of a reduced training subspace on the prediction accuracy of neural networks for hygrothermal predictions. Journal of Building Simulation Performance 2021, 14(1)

probabilistic input parameters, and was found to predict the hygrothermal performance of the massive masonry wall accurately. Yet, this network was trained to predict only for specific configurations in specific climates. The question rises whether such a metamodel is able to predict cases that the network was not trained on. In general, neural networks do not extrapolate well: they are used to fit a function on the provided training data, but outside the subspace populated with training points that function does not necessarily represent the correct relation [13-15]. As such, data fed to the network during inference (employing a trained network to make new predictions) must always lie within the training subspace. In [16], where a convolutional neural network (CNN) is used to predict the hygrothermal performance of a massive masonry wall, the authors showed that a CNN trained on Belgian climates is unable to predict accurately for Swedish and Italian climates, but conversely, a CNN trained on Swedish and Italian climates is able to accurately predict for Belgian climates. This reason for this is the range of the climate data: the training subspace with the Swedish and Italian climates also covered the Belgian climate data, thus the network could interpolate and predict accurately for the Belgian climates. In case of the training subspace with only Belgian climates, the network needed to extrapolate for the Swedish and Italian climates, resulting in inaccurate predictions.

This indicates that selecting the training set wisely could enable the network to predict accurately for a wider range of options, e.g. different climate locations or wall constructions, while saving training time, as not all options need to be included in the training dataset. Hence, this paper investigates whether training sets can be reduced by selecting subspaces without losing prediction accuracy. For this purpose, two exercises are conducted. The first exercise investigates the possibility to train a single network on a limited number of wall types and subsequently accurately predict the hygrothermal performance of wall types with different insulation thicknesses. This might be useful if the hygrothermal evaluation is part of a design process, where the best performing design option is the objective. The second exercise explores the possibility to train the network on a massive masonry wall configuration and a limited set of exterior climates and subsequently accurately predict the hygrothermal performance in other climates. This might be useful when the 
Postprint: Tijskens A., Janssen H., Roels S., 2020. The impact of a reduced training subspace on the prediction accuracy of neural networks for hygrothermal predictions. Journal of Building Simulation Performance 2021, 14(1)

https://doi.org/10.1080/19401493.2020.1832148

hygrothermal evaluation is required for a variety of climates, but only data about a limited number of climates is available at the time of network development.

The remainder of this paper starts with an explanation of the convolutional neural network architecture and performance evaluation in section 2, after which the simulation object used in the exercises is described in section 3. Subsequently, sections 4 and 5 describe the methodology, results and discussion of the first and second exercise respectively. Finally, the main conclusions from both exercises are summarised in section 6 .

\section{Convolutional neural network}

\subsection{Architecture}

For this research, the convolutional neural network (CNN) architecture developed in [12] is used. The network consists of dilated causal convolutions. The causality ensures that the network's output at a certain time step does not depend on future input time steps, whereas the dilations enable the network to access information from more past input time steps (i.e. the receptive field) with fewer layers. This principle is shown in Figure 1. For each additional layer, the dilation factor is increased exponentially, as this allows the receptive field to grow exponentially with network depth. To facilitate training, the dilated causal convolutions are incorporated in residual blocks, as shown in Figure 2. Each residual block starts with the dilated causal convolution, whose output is passed through a gated activation unit controlling the flow of information. Next, skip connections allow lower level signals to pass unfiltered to the final layers of the network, which allows the network to identify different aspects of the time series (i.e. strong autoregressive components, sophisticated trend and seasonality components). At the end, a residual connection is included, which bypasses the block's gated activation unit, to facilitate training deeper networks [17]. Additionally, to enable the network to produce output patterns for a specific context, the input to the gated activation unit is conditioned on an additional scalar input vector. This vector contains contextual time-invariant information, such as the wall orientation and configuration, but can also contain material characteristics if e.g. different brick types and insulation materials are included. Finally, to increase the receptive field, residual block are 
Postprint: Tijskens A., Janssen H., Roels S., 2020. The impact of a reduced training subspace on the prediction accuracy of neural networks for hygrothermal predictions. Journal of Building Simulation Performance 2021, 14(1)

https://doi.org/10.1080/19401493.2020.1832148

layered, with exponentially increasing dilatation rate. A combination of layered residual blocks are called stacks, which can also be repeated to increase the receptive field even further.

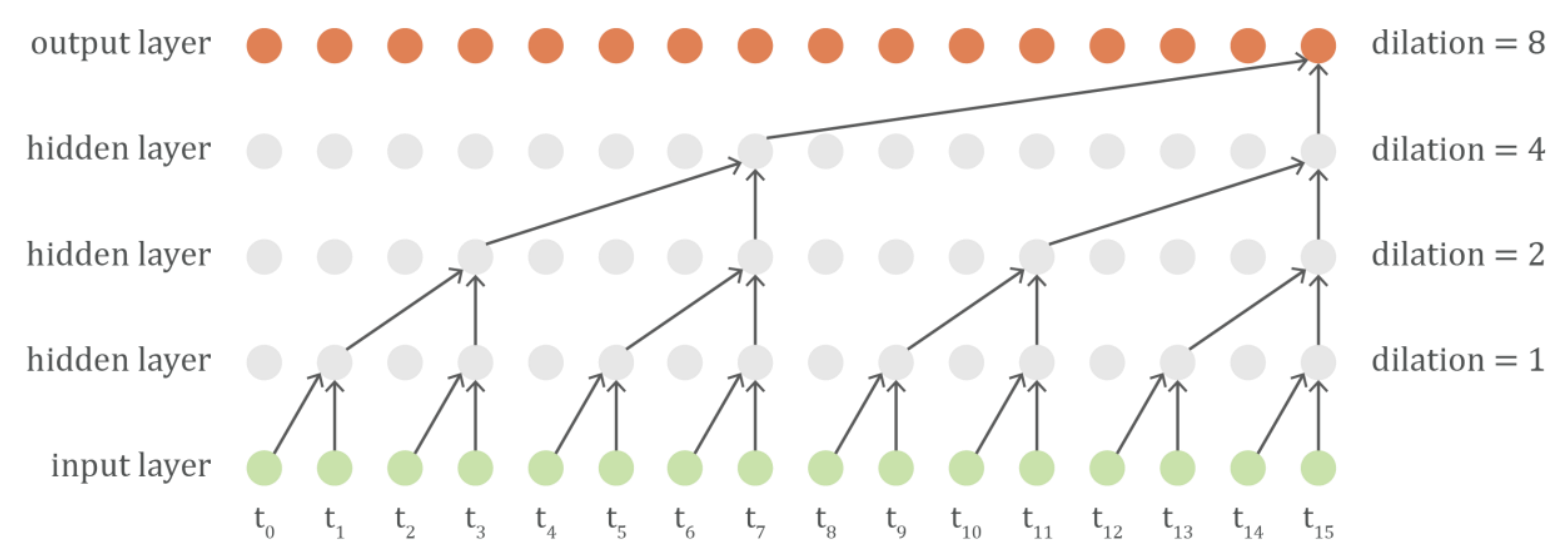

Figure 1: The causal dilated convolutions allow an output time step to receive information from a larger range of input time steps (i.e. the receptive field) with increasing number of hidden layers. In the presented scheme, a filter width of two, four layers and one stack result in a receptive field of sixteen input steps. 
Postprint: Tijskens A., Janssen H., Roels S., 2020. The impact of a reduced training subspace on the prediction accuracy of neural networks for hygrothermal predictions. Journal of Building Simulation Performance 2021, 14(1)

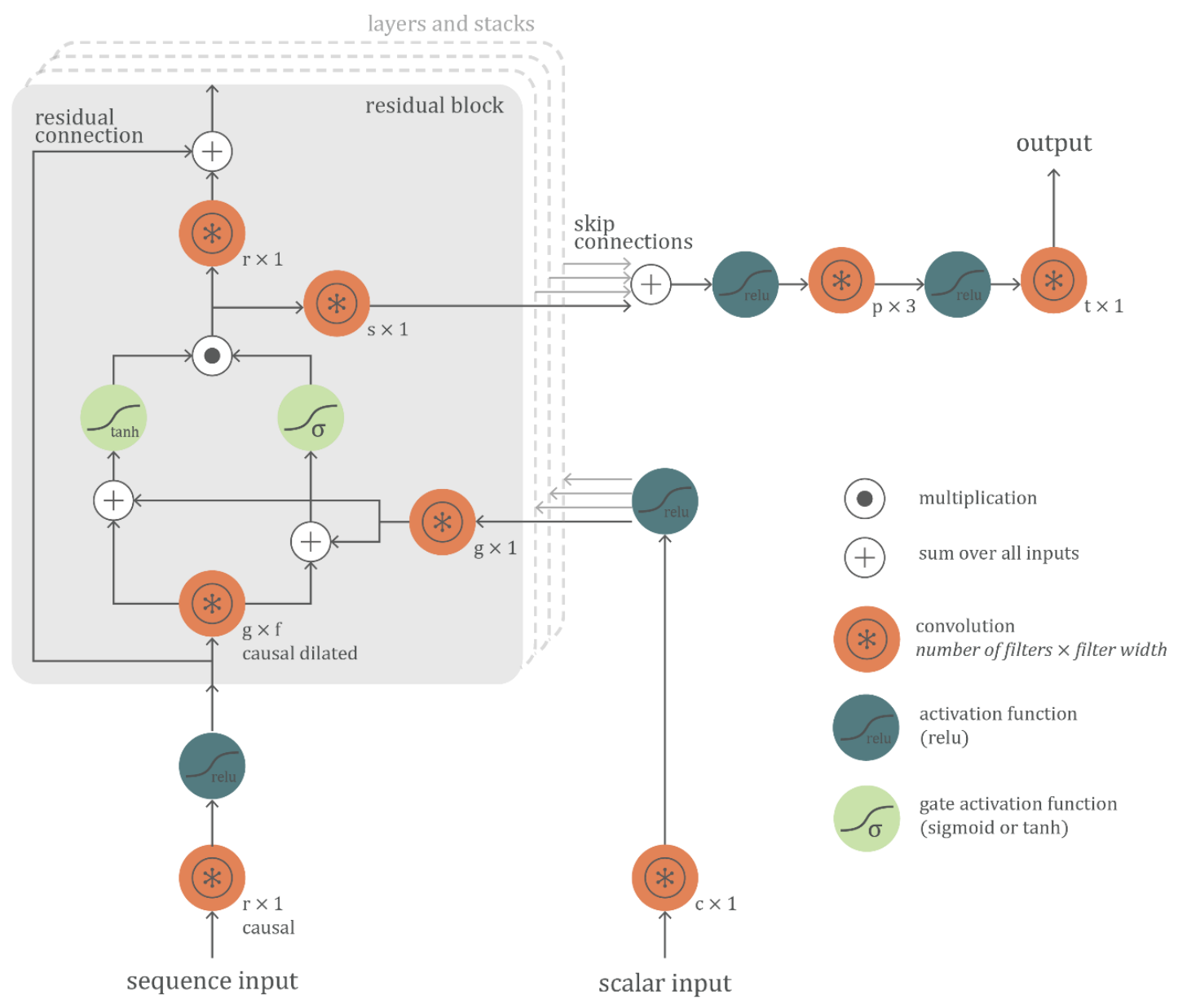

Figure 2: The used CNN architecture with residual blocks, skip connections and global conditioning.

A previous study [12] investigated the optimal values of the network's hyper-parameters (model configuration parameters that are external to the model and whose value cannot be estimated from the training data). Based on those findings, the following hyper-parameter values are used for the network in this study:

- Causal dilated convolution filter width $f$ of 10

- 128 of $c$-filters for initial conditional connection

- 128 of $g$-filters for gate connections

- 256 of $s$-filters for skip connections

- 256 of $r$-filters for residual connections

- 128 of $p$-filters for the penultimate connection

- 3 layers of residual blocks 
Postprint: Tijskens A., Janssen H., Roels S., 2020. The impact of a reduced training subspace on the prediction accuracy of neural networks for hygrothermal predictions. Journal of Building Simulation Performance 2021, 14(1)

- 3 stacks of layered residual blocks

\subsection{Performance evaluation}

The network is trained on a training dataset, and validated on a validation dataset. A maximum of 200 epochs is set, with early stopping if the RMSE on the validation dataset decreases less than 0.001 over 25 epochs. Training the network on a specific dataset is repeated five times, to overcome initialisation differences. The performance of these five neural networks is evaluated using two performance indicators: the root mean square error (RMSE) and the mean absolute error (MAE), quantified as follows:

$$
R M S E=\sqrt{\frac{1}{T} \sum(y-\hat{y})^{2}} \quad M A E=\frac{1}{T} \sum|y-\hat{y}|
$$

where $y$ is the true output, $\hat{y}$ is the predicted output and $T$ is the total number of data points. These indicators are calculated on the standardised data (zero mean, unit variance), as this ensures that errors are penalised equally for all targets. Additionally, the models' training time is evaluated.

Unless otherwise noted, the five training repetitions are referred to as one network for convenience. After training, the networks' performance is tested using an independent test set to obtain an unbiased performance evaluation. The two performance indicators are calculated for all targets combined, to facilitate comparison of the networks' performances, and for each target separately, to identify which targets are (not) accurately predicted. Subsequently, the network's output is used to predict the damage risks; these results are evaluated using the same two performance indicators as described above, calculated for each damage pattern separately on non-standardised data.

\section{Hygrothermal simulation object}

As in [12], the hygrothermal simulation object for the two exercises is a 1D cross section of a massive masonry wall, with (Exercise 1 in section 4) and without interior insulation (Exercise 2 in section 5). The masonry is simplified to an isotropic brick layer, no mortar joints [18] and construction details such as corners or 
Postprint: Tijskens A., Janssen H., Roels S., 2020. The impact of a reduced training subspace on the prediction accuracy of neural networks for hygrothermal predictions. Journal of Building Simulation Performance 2021, 14(1)

https://doi.org/10.1080/19401493.2020.1832148

embedded beams are modelled. To structure the contributing input parameters, a two-layer sampling scheme is adopted, separating the design layer and the uncertainty layer [1]. Design parameters, such as wall type, are controllable: they define the different design options and their values are known; these parameters define the design layer. In Exercise 1, the different interior insulation thicknesses define the design options; in Exercise 2, there is only one design option, a massive masonry wall. Inherently uncertain parameters, such as external climate and material characteristics, are completely uncontrollable: their values are neither known in the design process nor after, but they can significantly influence the design performance; these parameters are part of the uncertainty layer. All designs from the design layer are subjected to the same uncertainties from the uncertainty layer, as this allows reliable comparison of the design options' performance. Table 1 shows all characteristics and boundary conditions that are expected to significantly influence the hygrothermal performance of the $1 \mathrm{D}$ wall and are thus considered probabilistic; these parameters make up the uncertainty layer. Variability in climatic conditions is included by using different years of climate data. Depending on the exercise, different climate data is used. This will be clarified in the respective sections. Since the aim is to predict the expected future performance of the wall, climate data of ClimateForCulture [19] of the period $2020-2050$ is used. Variability in the wall conditions is incorporated via uniform distributions of the wall orientation, solar absorptance and exposure to wind-driven rain. The winddriven rain load is calculated by using the catch ratio as described in [20]. The catch ratio relates the winddriven rain (WDR) intensity on a facade to the unobstructed horizontal rainfall intensity and is a function of the reference wind speed and the horizontal rainfall intensity for a given position on the building facade and wind direction. In this model, variability in wall position and potential shelters, trees or surrounding buildings are reckoned with by the exposure factor. Additionally, the transiency and variation of the wind speed is taken into account in the convective heat transfer coefficient, via equation (2) (EN ISO 06946) where $h_{0}=$ $4 \mathrm{~W} / \mathrm{m}^{2} \mathrm{~K}$ and $k_{e}=1$.

$$
h_{c}=h_{0}+k_{s} \cdot v_{\text {wind }}^{k_{e}}
$$


Postprint: Tijskens A., Janssen H., Roels S., 2020. The impact of a reduced training subspace on the prediction accuracy of neural networks for hygrothermal predictions. Journal of Building Simulation Performance 2021, 14(1)

https://doi.org/10.1080/19401493.2020.1832148

The exterior moisture transfer coefficient is related to the exterior heat transfer coefficient through the Lewis relation. The interior climate is calculated according to EN 15026 [21] and variability in building use is included by using the two different humidity loads A and B. Finally, to explore the CNN's capabilities to the maximum, three different brick types as well as a uniform distribution of the wall thickness are included as well. The basic characteristics of the used brick types can be found in Table 2 and Figure 3, which clearly show the variations in the bricks' moisture properties.

The remaining parameters are all variables either with small variations or of less importance for the current study of a 1D wall, and are therefore assumed deterministic. Their constant values are given in Table 3.

Table 1: Probabilistic input parameters and distributions

\begin{tabular}{ll}
\hline Parameter & Value \\
\hline Exterior climate & $\mathrm{D}(\ldots)$ \\
Exterior climate start year & $\mathrm{D}(2020 ; 2047)$ \\
Wall orientation [degrees from North] & $\mathrm{U}(0 ; 360)$ \\
Solar absorptance $[-]$ & $\mathrm{U}(0.4 ; 0.8)$ \\
Ext. heat transfer coefficient slope $k_{S}\left[\mathrm{~J} / \mathrm{m}^{3} \mathrm{~K}\right]$ & $\mathrm{U}(1 ; 8)$ \\
WDR exposure factor $[-]$ & $\mathrm{U}(0 ; 2)$ \\
Brick wall thickness [m] & $\mathrm{U}(0.2 ; 0.5)$ \\
Brick material & $\mathrm{D}($ Brick 1; Brick 2; Brick 3) \\
Interior humidity load $[21]$ & $\mathrm{D}($ load A; load B) \\
\hline
\end{tabular}

$\mathrm{U}(\mathrm{a}, \mathrm{b})$ : uniform distribution between $\mathrm{a}$ and $\mathrm{b}$

$D(a, b)$ : discrete distribution between $a$ and $b$

Table 2: Brick material characteristics

\begin{tabular}{llll}
\hline Parameter & Brick 1 & Brick 2 & Brick 3 \\
\hline Dry thermal conductivity $\left[\mathrm{W} / \mathrm{m}^{2} \mathrm{~K}\right]$ & 0.87 & 0.52 & 1.00 \\
Dry vapour resistance factor $[-]$ & 139.52 & 13.25 & 19.00 \\
Capillary absorption coefficient $\left[\mathrm{kg} / \mathrm{m}^{2} \mathrm{~s}^{0.5}\right]$ & 0.046 & 0.357 & 0.100 \\
Capillary moisture content $\left[\mathrm{m}^{3} / \mathrm{m}^{3}\right]$ & 0.128 & 0.266 & 0.150 \\
Saturation moisture content $\left[\mathrm{m}^{3} / \mathrm{m}^{3}\right]$ & 0.240 & 0.367 & 0.250 \\
\hline
\end{tabular}


Postprint: Tijskens A., Janssen H., Roels S., 2020. The impact of a reduced training subspace on the prediction accuracy of neural networks for hygrothermal predictions. Journal of Building Simulation Performance 2021, 14(1)
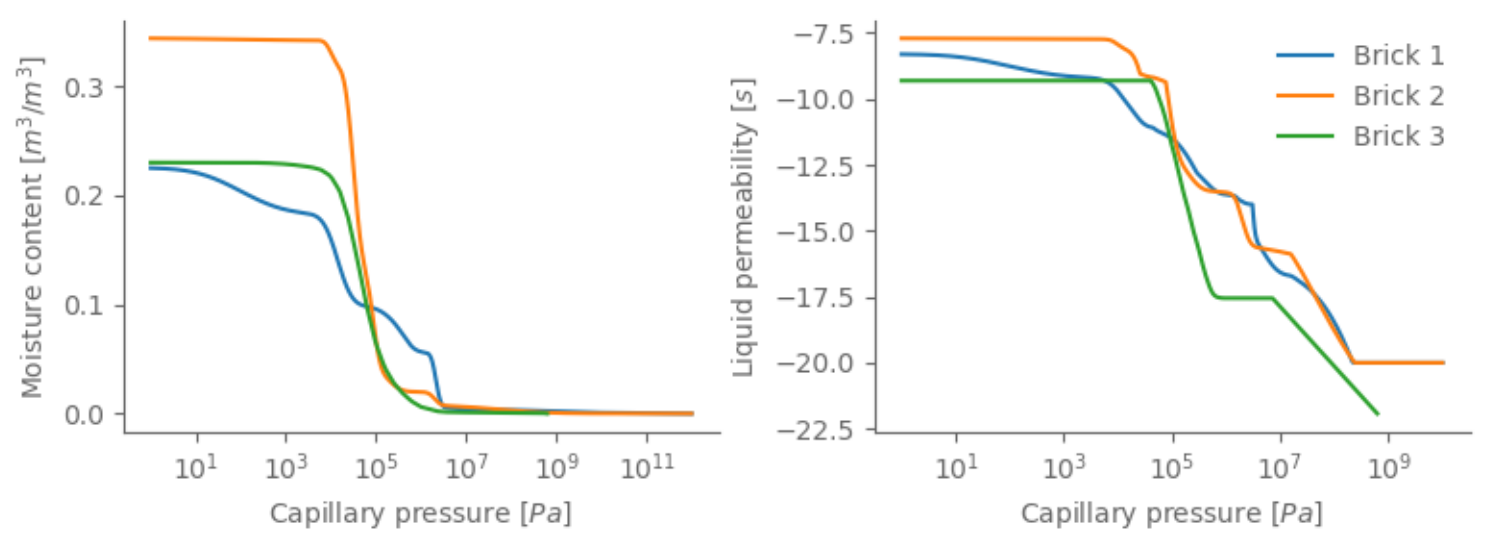

Figure 3: Brick type moisture properties

Table 3: Discrete input parameters

\begin{tabular}{ll}
\hline Parameter & Value \\
\hline $\begin{array}{l}\text { Exterior surface } \\
\text { Long wave emissivity }\end{array}$ & 0.9 \\
Interior surface & \\
Total heat transfer coefficient $\mathrm{h}\left[\mathrm{W} / \mathrm{m}^{2} \mathrm{~K}\right]$ & 8 \\
Moisture transfer coefficient $\beta[\mathrm{s} / \mathrm{m}]$ & $3 \times 10^{-8}$ \\
Initial conditions & \\
Initial temperature $\left[{ }^{\circ} \mathrm{C}\right]$ & 20 \\
Initial relative humidity $[\%]$ & 50 \\
\hline
\end{tabular}

When evaluating the hygrothermal performance of a massive masonry wall, one is typically interested in frost damage at the exterior surface, decay of embedded wooden floor beams and mould growth on the interior surface $[3,22-24]$. Table 4 gives an overview of the used prediction models for these damage patterns, and the required hygrothermal time series to evaluate them. Figure 4 schematically presents the 2D building component (top) and the modelled 1D mesh (bottom) and indicates at which positions the hygrothermal performance and damage patterns from Table 4 are monitored. The simulations were performed using the hygrothermal simulation environment Delphin 5.8 [25] and a simulation period of four years is adopted. As most damage prediction models require hourly data, an hourly output frequency is used. 
Postprint: Tijskens A., Janssen H., Roels S., 2020. The impact of a reduced training subspace on the prediction accuracy of neural networks for hygrothermal predictions. Journal of Building Simulation Performance 2021, 14(1)

https://doi.org/10.1080/19401493.2020.1832148

The frost damage risk is evaluated via the number of moist freeze-thaw cycles at $0.5 \mathrm{~cm}$ from the exterior surface. A 'moist' freeze-thaw cycle is a freeze-thaw cycle that occurs in combination with a moisture content high enough to induce frost damage [3]. In this study, the critical moisture content is defined as a moisture content above $25 \%$ of the saturated moisture content. Note that this is a rather arbitrary value, as currently no precise prediction criterion is at hand [26]. An indication of the decay risk of wooden beam ends can be made using the VTT wood decay model, which calculates the percentage of mass loss of the wooden beam end based on the temperature and relative humidity [27]. Note, however, that in this 1D wall study solely a rough indication of the wood decay risk is acquired, as only the conditions at the position of a wooden beam end are evaluated, while the actual beam is not modelled. Hence also other phenomena, such as two- and three-dimensional heat and moisture transport as well as potential air rotations around the wooden beam end are neglected [28]. At the interior surface, a too high relative humidity entails a risk on mould growth. The mould growth risk can be estimated by the VTT mould growth model, which calculates the Mould Index based on the fluctuation of the temperature and relative humidity [29]. The Mould Index is a value between 0 and 6, going from no growth to heavy and tight mould growth. In the updated VTT model, the expected material sensitivity to mould growth is implemented as well. In this study, the materials are assumed to belong to the class 'very sensitive'.

Table 4: Damage prediction models and required hygrothermal time series.

\begin{tabular}{clll}
\hline Position & Damage pattern & Prediction model & $\begin{array}{l}\text { Required hygrothermal } \\
\text { time series }\end{array}$ \\
\hline 1 & Frost damage & Moist freeze-thaw cycles & T, RH, saturation degree \\
2 & Decay of wooden beam ends & VTT wood decay model & T, RH \\
3 & Mould growth & Updated VTT mould growth model & T, RH \\
\hline T: temperature RH: relative humidity & & \\
\hline
\end{tabular}


Postprint: Tijskens A., Janssen H., Roels S., 2020. The impact of a reduced training subspace on the prediction accuracy of neural networks for hygrothermal predictions. Journal of Building Simulation Performance 2021, 14(1)

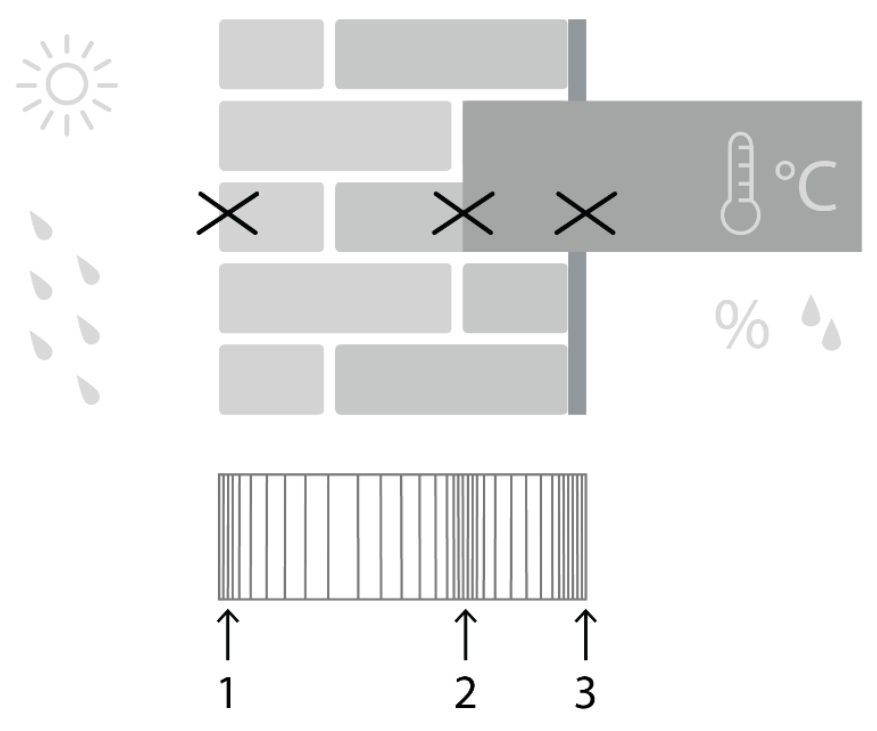

Figure 4: A schematic representation of the 2D building component (top) and the modelled 1D mesh (bottom), with indication at which positions the hygrothermal performance is monitored (Table 4).

The network is trained to predict hygrothermal time series as requested for the damage prediction models (see Table 4), based on the input in Table 1, Table 2 and Table 3. The inputs are pre-processed to facilitate learning. The scalar parameters 'wall orientation', 'exterior heat transfer coefficient slope', 'solar absorption' and 'rain exposure' are integrated in the exterior climate time series but also preserved as separate scalar input parameter, to condition the network (see Figure 2). The categorical parameters 'start year' and 'interior humidity load' are incorporated into the climate time series. The categorical parameter 'brick type' is replaced by scalar parameters of the characteristics given in Table 2. This simplifies the network architecture, and allows more flexibility on using brick types with differing characteristics. This results in 9 time series inputs (exterior temperature, exterior relative humidity, wind-driven rain load, wind speed, wind direction, short-wave radiation, long-wave sky radiation, interior temperature and interior relative humidity) and 10 scalar inputs (exterior heat transfer coefficient slope (eq. (2)), rain exposure factor, solar absorption, wall orientation, brick wall thickness and the five brick characteristics from Table 2). 
Postprint: Tijskens A., Janssen H., Roels S., 2020. The impact of a reduced training subspace on the prediction accuracy of neural networks for hygrothermal predictions. Journal of Building Simulation Performance 2021, 14(1)

https://doi.org/10.1080/19401493.2020.1832148

Before presenting the input and output data to the neural network, all data are standardised (zero mean, unit variance). This ensures that all features are on the same scale, which allows weighting all features equally in their representation. Standardising the output data ensures that errors are penalised equally for all targets.

\section{Exercise 1: predicting for different wall types}

\subsection{Methodology}

The first exercise investigates the possibility to train a network on a limited number of wall geometries and afterwards use it to predict the hygrothermal performance of other wall geometries. As this study is part of the European H2020 RIBuild project [30] on the application of internal insulation for historical buildings, the non-insulated massive masonry wall described in section 3 is supplemented by massive masonry walls with internal insulation of different thicknesses. The goal of this exercise is to train a network on a limited dataset that would allow it to predict the hygrothermal performance accurately for six wall types: a non-insulated massive masonry wall and five walls insulated with different thicknesses of PUR insulation -6, 10, 12, 14 and $18 \mathrm{~cm}$. These are the design options. The non-insulated wall is included to investigate whether the network is able to predict for different wall types rather than only different geometries of the same wall type. As a result, the test dataset, on which the trained networks' performance is evaluated, contains six wall types. To start, a training dataset with all six wall types (TrD-all) is defined as a reference. This allows comparing the prediction accuracy of the networks trained on a limited number of wall types to the accuracy of this reference network, trained on all wall types. Since the insulation thickness is a conditional input to the network and neural networks do not extrapolate well outside their training subspace, this subspace must include the minimum and maximum input values, i.e. the walls with 6 and $18 \mathrm{~cm}$ insulation. This allows the network to interpolate the other insulation thicknesses. Thus, the first training dataset (TrD-1) contains the uninsulated wall and the walls with 6 and $18 \mathrm{~cm}$ PUR insulation. To study whether adding a wall with an intermediate insulation thickness would increase prediction performance significantly, the wall with $12 \mathrm{~cm}$ insulation is added in the second dataset (TrD-2). Table 5 gives an overview of the different training datasets. 
Postprint: Tijskens A., Janssen H., Roels S., 2020. The impact of a reduced training subspace on the prediction accuracy of neural networks for hygrothermal predictions. Journal of Building Simulation Performance 2021, 14(1)

Table 5: Composition of the different training datasets.

\begin{tabular}{ccc} 
TrD-1 & TrD-2 & TrD-all \\
\hline Uninsulated wall & Uninsulated wall & Uninsulated wall \\
$6 \mathrm{~cm}$ PUR & $6 \mathrm{~cm}$ PUR & $6 \mathrm{~cm}$ PUR \\
$18 \mathrm{~cm}$ PUR & $12 \mathrm{~cm}$ PUR & $10 \mathrm{~cm}$ PUR \\
& $18 \mathrm{~cm}$ PUR & $12 \mathrm{~cm}$ PUR \\
& & $14 \mathrm{~cm}$ PUR \\
& & $18 \mathrm{~cm}$ PUR \\
\hline
\end{tabular}

All datasets are obtained by sampling the input parameters described in section 3 , using a Sobol sampling scheme [31] and simulating the deterministic HAM model once for each sampled input parameter combination. Each wall type is subjected to the same sampled values, to allow reliable comparison [1]. In this exercise, four West-European climates (Bergen, Dublin, Mannheim, London) are sampled. Similar to the brick types, the insulation material characteristics (shown in Table 6) and thickness are used as conditional input to the network to allow the network to distinguish the different wall types. In case of the uninsulated wall, these conditional input values are set to zero.

Table 6: Insulation material properties.

\begin{tabular}{lccccc}
\hline $\begin{array}{c}\text { Insulation } \\
\text { material }\end{array}$ & $\begin{array}{c}\text { Dry thermal } \\
\text { conductivity } \\
{\left[\mathrm{W} / \mathrm{m}^{2} \mathrm{~K}\right]}\end{array}$ & $\begin{array}{c}\text { Dry vapour } \\
\text { resistance } \\
\text { factor }[-]\end{array}$ & $\begin{array}{c}\text { Capillary moisture } \\
\text { content }\left[\mathrm{m}^{3} / \mathrm{m}^{3}\right]\end{array}$ & $\begin{array}{c}\text { Saturation } \\
\text { moisture content } \\
{\left[\mathrm{m}^{3} / \mathrm{m}^{3}\right]}\end{array}$ & $\begin{array}{c}\text { Capillary absorption } \\
\text { coefficient } \\
{\left[\mathrm{kg} / \mathrm{m}^{2} \mathbf{s} \mathbf{0 . 5}\right]}\end{array}$ \\
\hline PUR & 0.028 & 100 & 0.002 & 0.949 & $1 \mathrm{e}^{-7}$
\end{tabular}

Since there are six design options, the number of samples in the training datasets can be determined in two ways. The first is to choose an equal amount of samples per design option, i.e. wall type. This would result in datasets of different sizes, as each dataset has a different number of wall types. The second option is to choose a fixed size for the datasets and divide the total number of samples over the wall types present in the dataset. This would mean that datasets with a larger amount of wall types have fewer samples per wall type. Because training on a larger number of samples usually improves the mapping learned by the network, thus increasing the prediction accuracy, it might be hard to separate the influence of the number of samples from 
Postprint: Tijskens A., Janssen H., Roels S., 2020. The impact of a reduced training subspace on the prediction accuracy of neural networks for hygrothermal predictions. Journal of Building Simulation Performance 2021, 14(1)

https://doi.org/10.1080/19401493.2020.1832148

the influence of the number of wall types in the training dataset. Hence, both approaches are carried out. In case of the first option, all training datasets contain 512 training samples per wall type. In case of the second approach, all training datasets contain about 2048 total training samples - the exact number can vary a little, as it needs to be devisable by the number of wall types present in the dataset. This results per wall type in 680 training samples for TrD-1, 512 training samples for TrD-2 and 344 training samples for TrD-all. In both approaches, the validation sets always consist of 128 samples per wall type. Again, these numbers are chosen based on experience from other experiments, balancing accuracy and training time. After training the CNNs on the different datasets, ensuring good performance on the corresponding validation sets, their prediction performance is evaluated on the test dataset, which contains 128 samples per wall type.

\subsection{Results and discussion}

The trained networks' prediction performance on the test set is shown in Figure 5 (top and middle). When comparing the performances of the networks trained on 512 samples per wall type (left panels), it is clear that TrD-1-512 performs worse than the other two networks. In addition, the TrD-2-512 and TrD-all-512 networks have similar accuracy, whereas the training time (Figure 5, bottom left) of the TrD-all-512 networks is over 50 percent higher. Based on solely these results, one could think that this means that the more wall types in the training dataset, the better the prediction accuracy. However, when comparing the performances of the networks trained on datasets equal in size, with each about 2048 samples (right panels), the TrD-All-344 performs significantly worse than the other two networks. Furthermore, the performance of the network trained on TrD-1-680 improved over the network trained on TrD-1-512. This shows that training on all wall types does not necessarily result in better prediction accuracy, and that the number of training samples plays a significant role. This is confirmed by Figure 6, which shows the networks' prediction performance in function of the total amount of training samples and the number of wall types in the training dataset. These results indicate that training on a limited number of wall types but a larger amount of samples per wall type delivers a better performance, compared to training on all wall types and a smaller amount of 
Postprint: Tijskens A., Janssen H., Roels S., 2020. The impact of a reduced training subspace on the prediction accuracy of neural networks for hygrothermal predictions. Journal of Building Simulation Performance 2021, 14(1)

https://doi.org/10.1080/19401493.2020.1832148

samples per wall type (Figure 6). This can be explained by the fact that each design option (wall type) is subjected to the same samples of the uncertainty layer. As a result, training on fewer samples per wall type means that the network gets to see less data to capture the variability of the uncertainty layer, which clearly leads to a decrease in prediction performance. Hence, when training time is an issue, it is worthwhile to reduce the amount of wall types while increasing the number of training samples per wall type. 
Postprint: Tijskens A., Janssen H., Roels S., 2020. The impact of a reduced training subspace on the prediction accuracy of neural networks for hygrothermal predictions. Journal of Building Simulation Performance 2021, 14(1)

https://doi.org/10.1080/19401493.2020.1832148

Same number of samples per wall type

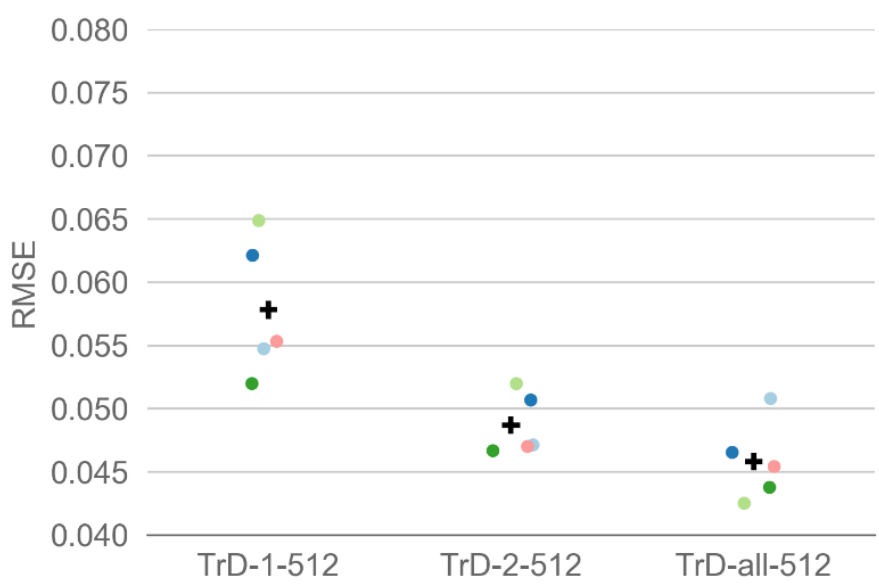

0.009

0.008
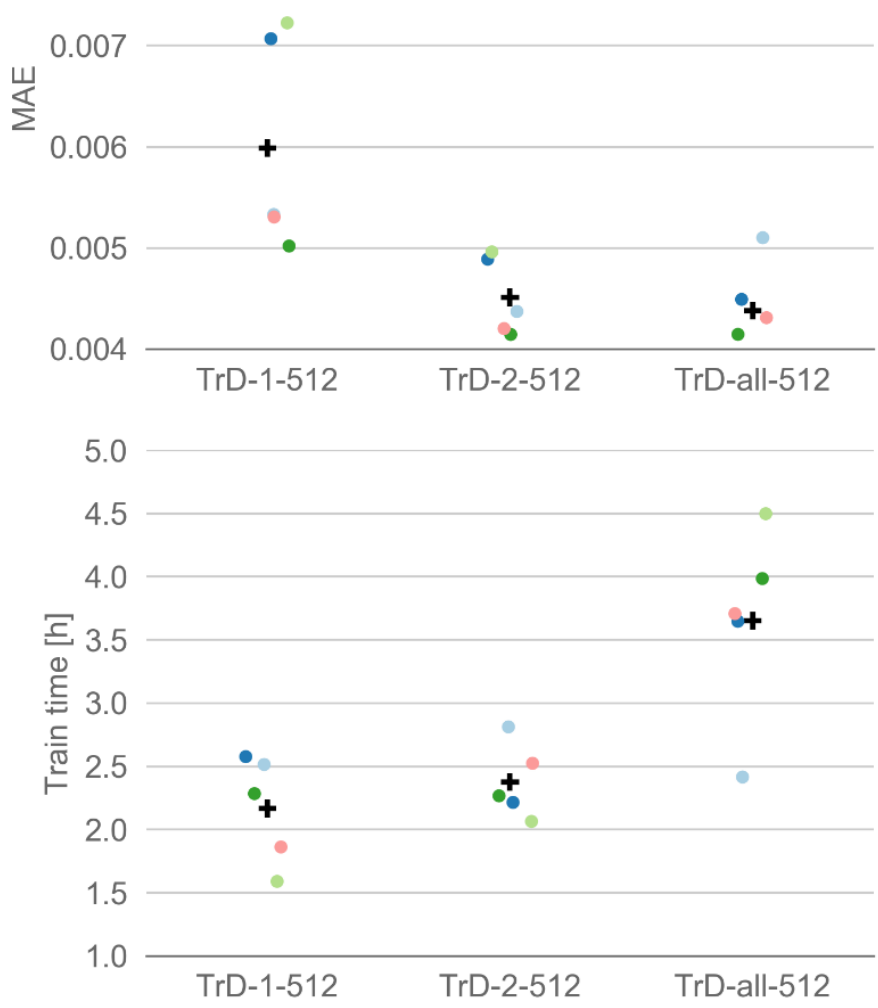

Same number of samples per dataset

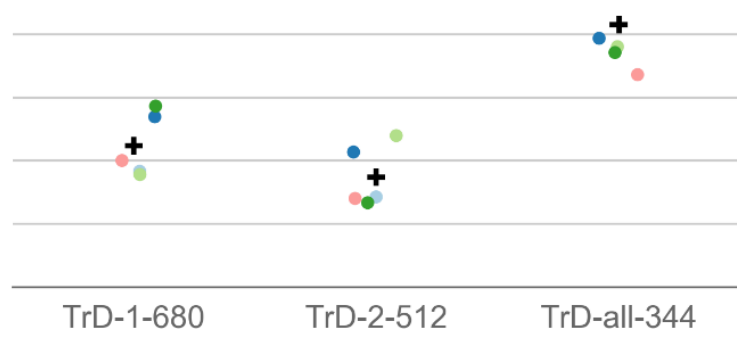

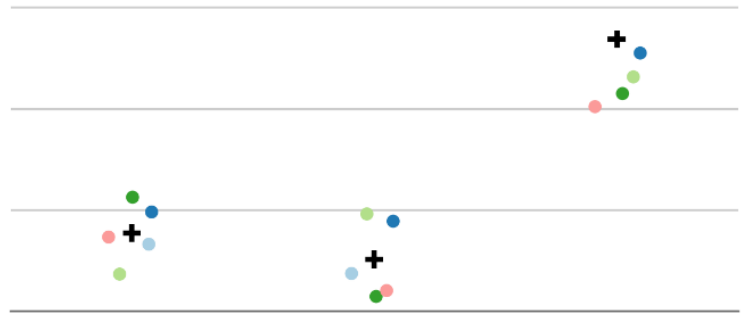

TrD-1-680 TrD-2-512 TrD-all-344

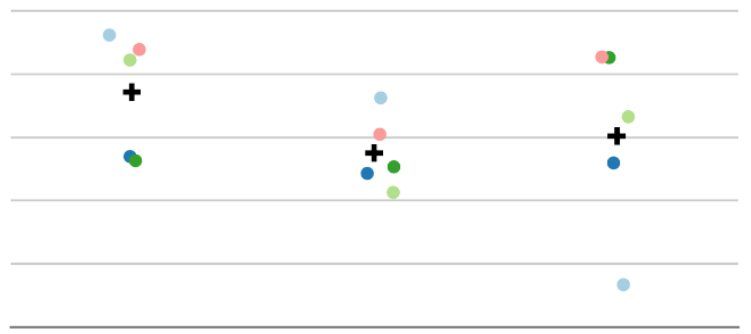

TrD-1-680 TrD-2-512 TrD-all-344

Figure 5: The prediction performance of the trained networks and their mean values (black crosses) for the reference test set (top and middle) and the corresponding train time (bottom), in function of the dataset size. 
Postprint: Tijskens A., Janssen H., Roels S., 2020. The impact of a reduced training subspace on the prediction accuracy of neural networks for hygrothermal predictions. Journal of Building Simulation Performance 2021, 14(1)

https://doi.org/10.1080/19401493.2020.1832148
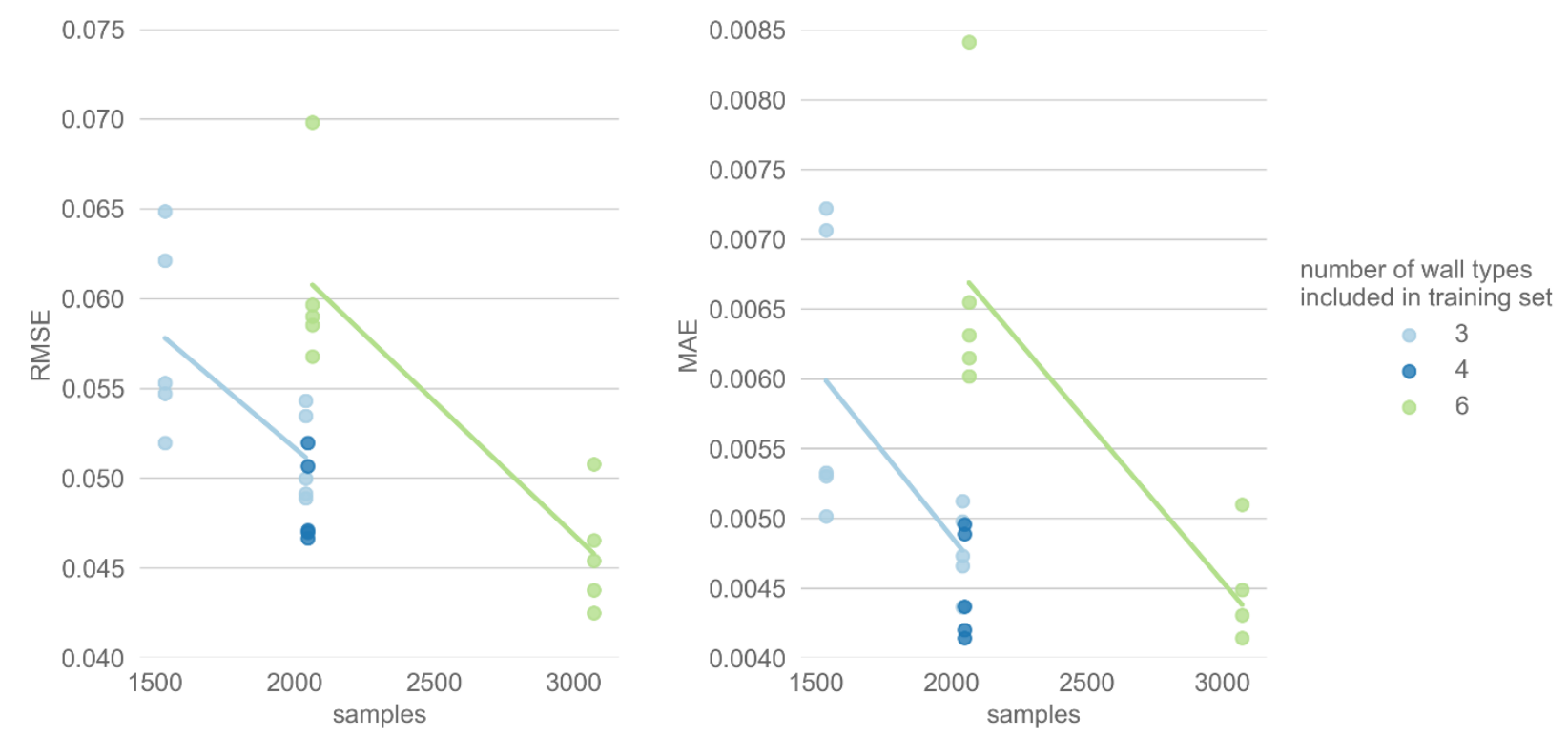

Figure 6: Network prediction performance in function of the number of training samples and wall types, with a linear regression line to show the evolution of performance with increasing number of training samples.

Using the most accurate network trained on TrD-2-512, Figure 7 shows the hygrothermal response of one sample of a wall with $10 \mathrm{~cm}$ insulation thickness (orange), which was not included in the TrD-2-512 training set. This confirms that it is possible to obtain high accuracy for wall types that the network was not trained on. The damage predictions for the test set, using the same network, are shown in Figure 8 . The red dots are test set samples with a wall type that the network was trained on, the blue dots are test set samples with interpolated insulation thicknesses. These results show as well that a high damage prediction accuracy can be obtained for interpolated insulation thicknesses. 
Postprint: Tijskens A., Janssen H., Roels S., 2020. The impact of a reduced training subspace on the prediction accuracy of neural networks for hygrothermal predictions. Journal of Building Simulation Performance 2021, 14(1)
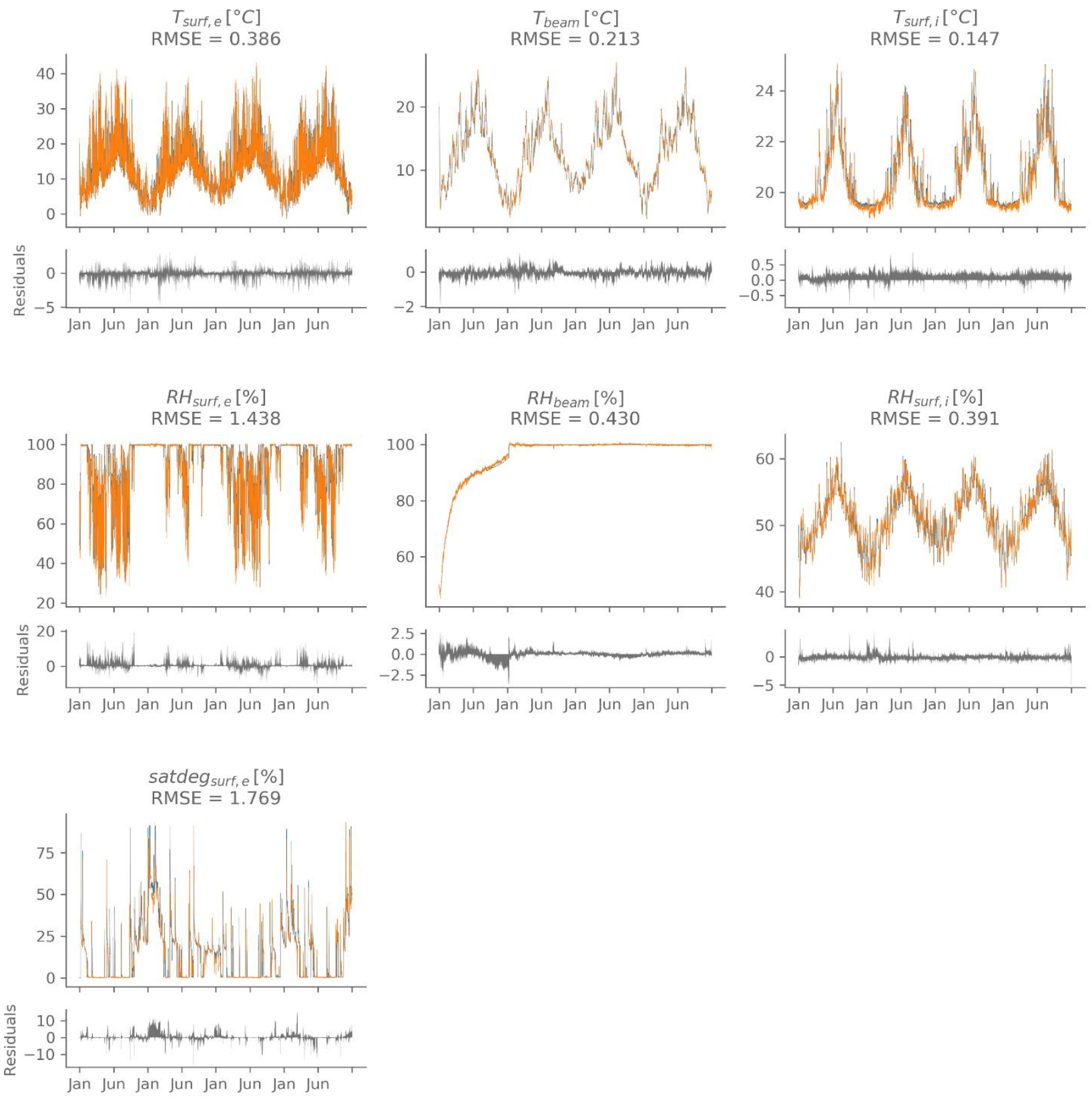

Figure 7: The hygrothermal response of one sample from the test set with $10 \mathrm{~cm}$ insulation thickness, as predicted by the network trained on TrD-2-512 (orange), the true value (blue) and the errors (grey). 
Postprint: Tijskens A., Janssen H., Roels S., 2020. The impact of a reduced training subspace on the prediction accuracy of neural networks for hygrothermal predictions. Journal of Building Simulation Performance 2021, 14(1)
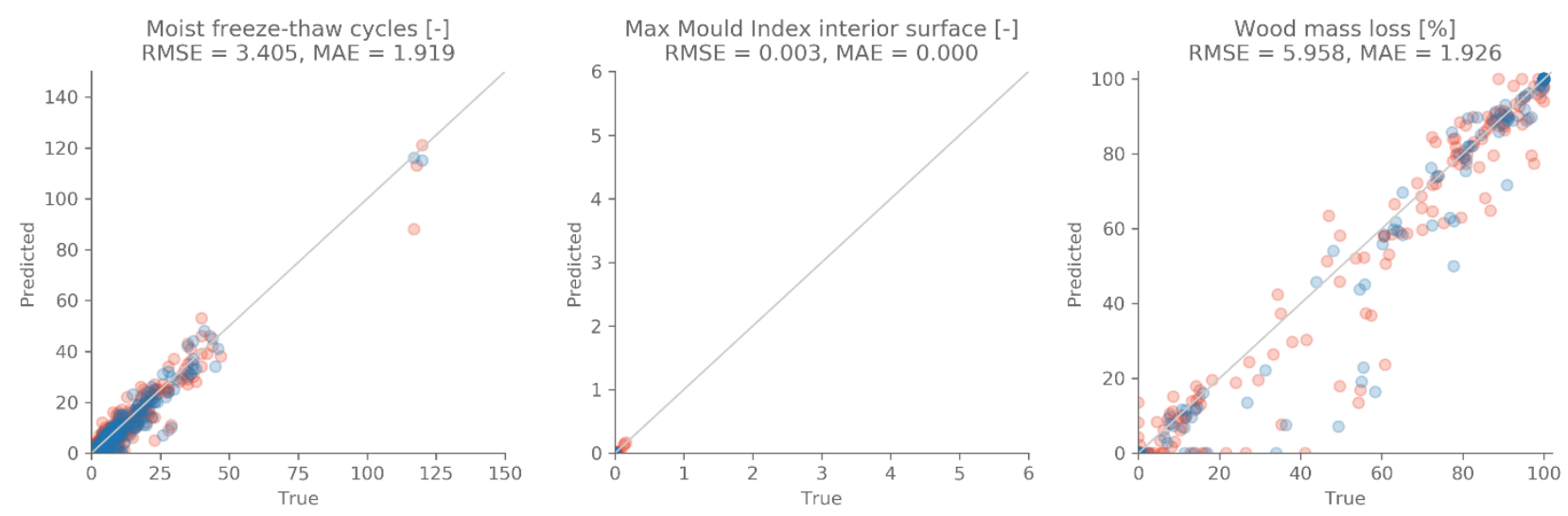

Figure 8: The damage prediction accuracy for the test set, using the network trained on TrD-2-512. To show whether there is a performance difference, the test set samples with a wall type also used during training are shown in red, while the samples of interpolated wall types, with an insulation thickness not used during training, are shown in blue.

\section{Exercise 2: predicting for different climates}

\subsection{Methodology}

The second exercise investigates the possibility to train the network on a limited number of exterior climates and afterwards use it to predict the hygrothermal performances for other climates as well. To this purpose, a reference set of 80 climate locations, geographically distributed over Europe, is selected from [32]. To evaluate the trained networks' performance on unseen data, a test dataset containing all these 80 climate locations is generated. Next, a training dataset containing all 80 climate locations ( $T r D-a l l)$ is composed as a reference, to compare the accuracy of the networks trained on a reduced subspace. Because neural networks do not extrapolate well for data outside the training subspace, the climate locations selected for the training dataset must include the minimum and maximum value of each input feature (exterior temperature, exterior relative humidity, wind-driven rain load, wind speed, wind direction, short-wave radiation, long-wave sky radiation, interior temperature and interior relative humidity). Hence, the climate data of the test set is analysed and the minimum and maximum values per climate location are shown in Table 7. Note that in case of the short wave radiation and the wind-driven rain load, this is the pre-processed data, which includes the sample's wall orientation and solar absorptance as explained in section 3. The total wind-driven rain load is 
Postprint: Tijskens A., Janssen H., Roels S., 2020. The impact of a reduced training subspace on the prediction accuracy of neural networks for hygrothermal predictions. Journal of Building Simulation Performance 2021, 14(1)

https://doi.org/10.1080/19401493.2020.1832148

the sum of the wind-driven rain load time steps, averaged over all samples using the considered climate location. It thus provides information on the average total amount for wind-driven rain a wall on the considered climate location is exposed to over the entire simulation period. In case of the interior temperature and relative humidity, the limits are defined by EN 15026 and thus are the same for the training and test datasets. Furthermore, some climate parameters have natural lower or upper bounds that are identical for all climate locations, i.e. the relative humidity has an upper bound of $100 \%$ and the radiation and wind-driven rain load have a lower bound of $0 \mathrm{~W} / \mathrm{m} 2$ and $0 \mathrm{~mm}$. Hence, these minimum and maximum values do not need to be considered when selecting the representative climate locations for the training dataset, and thus are not shown in Table 7. 
Postprint: Tijskens A., Janssen H., Roels S., 2020. The impact of a reduced training subspace on the prediction accuracy of neural networks for hygrothermal predictions. Journal of Building Simulation Performance 2021, 14(1)

Table 7: The Köppen-Geiger classification and the minimum and maximum values of the climate data for each geographical location in the test set.

\begin{tabular}{|c|c|c|c|c|c|c|c|c|c|c|}
\hline & $\begin{array}{l}\text { Köppen- } \\
\text { Geiger }\end{array}$ & $\begin{array}{c}\text { Relative } \\
\text { Humidity min } \\
\text { [\%] } \\
\end{array}$ & $\begin{array}{l}\text { Temperature } \\
\min \left[{ }^{\circ} \mathrm{C}\right]\end{array}$ & $\begin{array}{c}\text { Temperature } \\
\max \left[{ }^{\circ} \mathrm{C}\right]\end{array}$ & $\begin{array}{l}\text { Wind Speed } \\
\max [\mathrm{m} / \mathrm{s}]\end{array}$ & $\begin{array}{l}\text { Long-wave } \\
\text { Sky Radiation } \\
\min [\mathrm{m} / \mathrm{s}]\end{array}$ & $\begin{array}{c}\text { Long-wave } \\
\text { Sky Radiation } \\
\max [\mathrm{W} / \mathrm{m} 2]\end{array}$ & $\begin{array}{c}\text { Short Wave } \\
\text { Radiation } \\
\max [\mathrm{W} / \mathrm{m} 2]\end{array}$ & $\begin{array}{l}\text { Wind-Driven } \\
\text { Rain load } \\
\max [\mathrm{mm}] \\
\end{array}$ & $\begin{array}{l}\text { Total wind- } \\
\text { driven rain } \\
\text { load }[\mathrm{mm}]\end{array}$ \\
\hline Almeria & Bsk & 6 & 2,7 & 41,0 & 16,5 & 295 & 505 & 1116 & 8,7 & 108 \\
\hline Arjeplog & Dfc & 37 & $-40,6$ & 20,5 & 17,8 & 193 & 376 & 790 & 3,7 & 493 \\
\hline Athinai & Csa & 6 & $-1,1$ & 47,2 & 12,3 & 281 & 554 & 799 & 11,1 & 60 \\
\hline Aviemore & $\mathrm{Cfc}$ & 18 & $-15,2$ & 27,6 & 18,9 & 222 & 424 & 842,5 & 2,8 & 129 \\
\hline Bastia & Csa & 7 & $-5,9$ & 37,8 & 16,0 & 263 & 488 & 853,5 & 12,2 & 230 \\
\hline Beograd & $\mathrm{Cfa}$ & 7 & $-20,1$ & 44,9 & 13,4 & 214 & 544 & 784 & 3,0 & 111 \\
\hline Bergen & $\mathrm{Cfb}$ & 28 & $-16,5$ & 23,5 & 16,8 & 225 & 399 & 700 & 3,1 & 175 \\
\hline Bilbao & $\mathrm{Cfb}$ & 11 & $-0,7$ & 42,8 & 14,5 & 282 & 513 & 995,5 & 1,4 & 27 \\
\hline Bitola & $\mathrm{Cfb}$ & 5 & $-24,9$ & 45,0 & 15,2 & 189 & 549 & 877 & 10,7 & 55 \\
\hline Bodo & $\mathrm{Cfc}$ & 28 & $-10,7$ & 18,6 & 30,0 & 287 & 354 & 746,5 & 16,6 & 246 \\
\hline Bologna & $\mathrm{Cfa}$ & 6 & $-14,8$ & 45,3 & 13,7 & 224 & 551 & 579 & 4,9 & 127 \\
\hline Bordeaux & $\mathrm{Cfb}$ & 14 & $-3,4$ & 40,2 & 14,7 & 272 & 498 & 977,5 & 3,9 & 34 \\
\hline Brasov & Dfb & 5 & $-26,4$ & 40,9 & 15,0 & 185 & 509 & 951,5 & 2,7 & 54 \\
\hline Brest & $\mathrm{Cfb}$ & 28 & $-2,3$ & 31,4 & 20,2 & 275 & 449 & 898 & 4,7 & 120 \\
\hline Brindisi & Csa & 13 & 4,2 & 37,0 & 22,6 & 328 & 438 & 683,5 & 17,6 & 249 \\
\hline Bucuresti & Dfa & 6 & $-21,7$ & 48,1 & 13,3 & 201 & 563 & 837,5 & 5,8 & 186 \\
\hline Budapest & Dfa & 10 & $-17,3$ & 42,3 & 12,3 & 218 & 515 & 841,5 & 2,6 & 80 \\
\hline Cagliari & Csa & 5 & $-1,3$ & 46,1 & 15,3 & 279 & 550 & 576 & 17,5 & 99 \\
\hline Cardiff & $\mathrm{Cfb}$ & 26 & $-11,0$ & 29,0 & 17,2 & 243 & 435 & 761,5 & 11,3 & 352 \\
\hline Chirpan & $\mathrm{Cfa}$ & 6 & $-25,2$ & 48,0 & 12,7 & 188 & 574 & 957 & 5,1 & 119 \\
\hline Clermont-Ferrand & $\mathrm{Cfb}$ & 7 & $-19,9$ & 39,7 & 12,6 & 205 & 483 & 843,5 & 2,0 & 12 \\
\hline Debrecen & Dfb & 9 & $-22,6$ & 43,5 & 14,9 & 197 & 532 & 849 & 3,4 & 48 \\
\hline Dublin & $\mathrm{Cfb}$ & 37 & $-8,9$ & 29,0 & 16,5 & 250 & 432 & 843 & 6,1 & 306 \\
\hline Dubrovnik & Csa & 6 & $-7,4$ & 40,4 & 16,2 & 266 & 499 & 901,5 & 9,7 & 589 \\
\hline Embrun & Dfb & 7 & $-28,2$ & 30,1 & 8,8 & 182 & 426 & 816 & 2,3 & 128 \\
\hline Faro & Csa & 9 & 4,5 & 35,8 & 22,0 & 326 & 458 & 1259 & 18,0 & 112 \\
\hline Gaasbeek & $\mathrm{Cfb}$ & 22 & $-20,7$ & 35,3 & 15,2 & 204 & 459 & 748,5 & 1,6 & 47 \\
\hline Gouverniotissa & Csa & 5 & 2,1 & 42,9 & 15,3 & 297 & 523 & 1024 & 7,0 & 27 \\
\hline Groningen & $\mathrm{Cfb}$ & 26 & $-12,8$ & 33,8 & 14,7 & 236 & 450 & 763 & 4,0 & 99 \\
\hline Hamburg & $\mathrm{Cfb}$ & 23 & $-21,9$ & 37,2 & 12,9 & 202 & 472 & 789,5 & 3,7 & 96 \\
\hline Helsinki & Dfb & 31 & $-31,6$ & 31,3 & 12,9 & 172 & 449 & 924 & 4,9 & 241 \\
\hline Innsbruck & Dfb & 9 & $-32,6$ & 31,6 & 9,1 & 167 & 430 & 917,5 & 0,5 & 18 \\
\hline Jyväskylä & Dfc & 37 & $-35,1$ & 27,7 & 11,3 & 161 & 419 & 627 & 4,5 & 178 \\
\hline Karlstad & $\mathrm{Dfb}$ & 33 & $-14,3$ & 22,0 & 20,1 & 261 & 374 & 713 & 11,9 & 881 \\
\hline Kevo & Dfc & 28 & $-42,9$ & 26,2 & 13,6 & 141 & 412 & 1018,5 & 3,0 & 217 \\
\hline Kiev & Dfb & 13 & $-28,2$ & 40,9 & 13,5 & 182 & 514 & 966,5 & 11,8 & 119 \\
\hline
\end{tabular}


Postprint: Tijskens A., Janssen H., Roels S., 2020. The impact of a reduced training subspace on the prediction accuracy of neural networks for hygrothermal predictions. Journal of Building Simulation Performance 2021, 14(1)

https://doi.org/10.1080/19401493.2020.1832148

\begin{tabular}{|c|c|c|c|c|c|c|c|c|c|c|}
\hline Kiruna & Dfc & 17 & $-47,3$ & 24,1 & 11,8 & 137 & 400 & 758,5 & 1,7 & 180 \\
\hline Kolobrzeg & Dfb & 26 & $-14,9$ & 32,3 & 20,8 & 234 & 438 & 696,5 & 10,6 & 173 \\
\hline Kovenhavn & Dfb & 24 & $-19,7$ & 31,1 & 15,3 & 211 & 439 & 686 & 7,2 & 228 \\
\hline La Coruña & Csb & 22 & 1,9 & 34,6 & 14,4 & 297 & 447 & 1052 & 4,6 & 48 \\
\hline Lerwick & $\mathrm{Cfc}$ & 27 & $-0,6$ & 18,4 & 28,6 & 302 & 371 & 764,5 & 16,0 & 1085 \\
\hline Liepaya & Dfb & 27 & $-19,7$ & 28,1 & 18,2 & 215 & 425 & 819,5 & 7,0 & 180 \\
\hline Lillehammer & Dfc & 16 & $-39,0$ & 28,0 & 11,3 & 153 & 419 & 666 & 7,7 & 372 \\
\hline Linz & Dfb & 14 & $-24,5$ & 38,2 & 14,9 & 190 & 471 & 794 & 2,5 & 59 \\
\hline London & $\mathrm{Cfb}$ & 20 & $-5,7$ & 35,2 & 9,3 & 261 & 467 & 711 & 3,0 & 58 \\
\hline Lulea & Dfc & 46 & $-30,4$ & 16,6 & 20,7 & 199 & 354 & 715 & 6,4 & 625 \\
\hline Luzern & $\mathrm{Cfb}$ & 14 & $-27,5$ & 36,4 & 13,9 & 185 & 450 & 624,5 & 1,0 & 37 \\
\hline Madrid & Bsk & 7 & $-3,3$ & 44,0 & 12,1 & 269 & 540 & 968,5 & 2,4 & 66 \\
\hline Mannheim & $\mathrm{Cfb}$ & 22 & $-22,4$ & 39,9 & 11,9 & 197 & 481 & 683,5 & 1,9 & 36 \\
\hline Montpellier & Csa & 15 & $-11,6$ & 42,9 & 15,1 & 236 & 497 & 840 & 2,6 & 42 \\
\hline Napoli & Csa & 11 & $-0,5$ & 43,0 & 13,6 & 287 & 523 & 833 & 5,6 & 92 \\
\hline Newcastle & $\mathrm{Cfb}$ & 27 & $-14,6$ & 31,6 & 15,3 & 224 & 444 & 733 & 5,8 & 257 \\
\hline Odessa & Bsk & 13 & $-15,1$ & 40,8 & 14,8 & 227 & 516 & 843 & 19,6 & 120 \\
\hline Olavinlinna & Dfc & 42 & $-33,9$ & 24,6 & 14,0 & 176 & 404 & 995,5 & 7,2 & 306 \\
\hline Östersund & Dfc & 32 & $-36,9$ & 26,3 & 15,0 & 167 & 411 & 684 & 2,0 & 269 \\
\hline Palermo & Csa & 6 & 0,2 & 44,1 & 14,5 & 286 & 530 & 876,5 & 5,4 & 55 \\
\hline Palma De Mallorca & Bsk & 14 & 1,4 & 38,6 & 17,1 & 295 & 497 & 821 & 14,8 & 92 \\
\hline Paris & $\mathrm{Cfb}$ & 23 & $-9,9$ & 37,3 & 10,4 & 245 & 478 & 772,5 & 1,0 & 28 \\
\hline Pleven & Dfa & 5 & $-19,6$ & 48,6 & 15,8 & 207 & 578 & 802,5 & 9,5 & 126 \\
\hline Porto & Csb & 9 & 0,6 & 41,2 & 15,7 & 290 & 502 & 1295 & 4,8 & 57 \\
\hline Potsdam & Dfb & 25 & $-23,3$ & 38,0 & 15,5 & 201 & 470 & 745 & 3,1 & 73 \\
\hline Prag & Dfb & 20 & $-25,9$ & 39,1 & 11,9 & 187 & 477 & 807,5 & 6,3 & 44 \\
\hline Qrendi & Csa & 19 & 5,6 & 34,9 & 27,2 & 311 & 486 & 950,5 & 63,1 & 268 \\
\hline Riga & Dfb & 30 & $-35,3$ & 31,6 & 14,6 & 160 & 442 & 867 & 10,1 & 160 \\
\hline Sodankylä & Dfc & 39 & $-42,2$ & 26,0 & 9,1 & 144 & 406 & 999 & 2,1 & 138 \\
\hline Stockholm & Dfb & 36 & $-27,6$ & 27,6 & 11,5 & 189 & 419 & 758,5 & 4,9 & 162 \\
\hline Strbskepleso & Dfc & 7 & $-26,0$ & 31,9 & 12,2 & 189 & 445 & 807,5 & 2,2 & 35 \\
\hline Suwalki & Dfb & 27 & $-30,1$ & 33,1 & 13,9 & 176 & 451 & 703,5 & 4,8 & 138 \\
\hline The Hague & $\mathrm{Cfb}$ & 35 & $-6,5$ & 26,3 & 20,7 & 289 & 395 & 783 & 5,8 & 169 \\
\hline Thessaloniki & Bsk & 7 & $-1,9$ & 36,9 & 15,2 & 310 & 442 & 780,5 & 9,7 & 257 \\
\hline Trieste & $\mathrm{Cfa}$ & 12 & $-4,4$ & 31,5 & 20,3 & 299 & 415 & 661 & 15,9 & 899 \\
\hline Troms $\varnothing$ & Dfc & 22 & $-27,8$ & 24,0 & 16,0 & 194 & 400 & 946 & 3,9 & 73 \\
\hline Valentia Island & $\mathrm{Cfb}$ & 30 & 0,0 & 25,3 & 22,8 & 289 & 411 & 936 & 5,1 & 282 \\
\hline Varna & $\mathrm{Cfa}$ & 11 & $-4,8$ & 33,7 & 20,9 & 311 & 418 & 981,5 & 10,0 & 248 \\
\hline Vigrestad & $\mathrm{Cfb}$ & 33 & $-6,1$ & 21,5 & 21,3 & 276 & 380 & 639 & 11,8 & 903 \\
\hline Visby & Dfb & 32 & $-24,7$ & 31,6 & 14,0 & 194 & 450 & 809 & 7,8 & 138 \\
\hline Warszawa & Dfb & 22 & $-32,2$ & 36,4 & 13,9 & 171 & 471 & 803 & 9,9 & 107 \\
\hline
\end{tabular}


Postprint: Tijskens A., Janssen H., Roels S., 2020. The impact of a reduced training subspace on the prediction accuracy of neural networks for hygrothermal predictions. Journal of Building Simulation Performance 2021, 14(1)

\begin{tabular}{llrrrrrrrrr} 
Weimar & Dfb & 21 & $-23,9$ & 38,0 & 14,6 & 194 & 473 & 773,5 & 4,9 & 52 \\
Wien & Dfb & 20 & $-25,4$ & 38,8 & 14,0 & 190 & 491 & 810,5 & 1,8 & 44 \\
\hline Zagreb & $\mathrm{Cfb}$ & 9 & $-21,4$ & 44,0 & 12,1 & 202 & 527 & 773 & 3,1 & 100 \\
\hline
\end{tabular}


Postprint: Tijskens A., Janssen H., Roels S., 2020. The impact of a reduced training subspace on the prediction accuracy of neural networks for hygrothermal predictions. Journal of Building Simulation Performance 2021, 14(1)

This analysis shows that the climates of Bodo, Kiruna, Qrendi, Pleven and Porto contain the absolute minima and maxima and thus define the outer limits of the training subspace. Hence, the first training dataset (TrD1) contains only these five climates. But even though the selected five climates contain the minima and maxima, this is no guarantee that all other climates are represented by this subspace, since there is a lot of variance between them. This variance results in different hygrothermal responses in the massive masonry wall. Therefore, the next training sets are inspired by the Köppen-Geiger climate classification [33]. This classification divides climates into five main climate groups, with each group further divided based on seasonal precipitation and temperature patterns. These climate classes might also account for the differences in hygrothermal performance, thus the next two datasets are defined by selecting one climate from each class, on top of the five required climate locations defining the outer limits of the training subspace. For TrD-2, four additional climate locations are chosen with an average total wind-driven rain load. Since the total wind-driven rain load significantly influences the hygrothermal response of massive masonry walls, in TrD-3, the climate locations with the highest total wind-driven rain load over the entire 4-year simulation period are chosen. Finally, TrD-4 is composed by selecting two locations from climate classes represented by more than 10 climate locations, while ensuring the training set is representative for all winddriven rain loads. Table 8 gives an overview of the different training datasets and the climate locations that are included.

Table 8: Composition of the different training datasets.

\begin{tabular}{cccc} 
TrD-1 & TrD-2 & TrD-3 & TrD-4 \\
\hline Bodo & Bodo & Bodo & Bodo \\
Kiruna & Kiruna & Kiruna & Kiruna \\
Qrendi & Qrendi & Qrendi & Qrendi \\
Pleven & Pleven & Pleven & Pleven \\
Porto & Porto & Porto & Porto \\
& Riga & Karlstad & Odessa \\
& The Hague & Vigrestad & Varna \\
& Almeria & Thessaloniki & London \\
& Varna & Trieste & Vigrestad \\
& & & Faro
\end{tabular}


Postprint: Tijskens A., Janssen H., Roels S., 2020. The impact of a reduced training subspace on the prediction accuracy of neural networks for hygrothermal predictions. Journal of Building Simulation Performance 2021, 14(1)

https://doi.org/10.1080/19401493.2020.1832148

\author{
Helsinki \\ Riga \\ Lillehammer
}

In this exercise, there is only one design option, i.e. the massive masonry wall. Hence, it makes sense to create datasets of similar size. Therefore, all training datasets contain 1280 samples, of which 1024 are used for training and 256 for validation. Previous experiments showed that this number of samples results in an adequate prediction performance, but note that a larger training set might result in higher accuracy. As this is an explorative study, the balance between accuracy and training time is chosen in favour of a shorter training time. As each dataset contains the same number of samples, the datasets that contain fewer climate locations contain more samples per climate, compared to the dataset with all climate locations (TrD-all). Hence, one might expect that datasets with fewer climate locations require fewer samples to obtain accurate prediction results. To test this, the networks are also trained on only 512 samples of the datasets. The test set, used to evaluate the trained networks, contains 1024 samples. All datasets are obtained by sampling the input parameters described in section 3, using a Sobol sampling scheme [31] and simulating the deterministic HAM model once for each sampled input parameter combination. After the CNNs are trained on the different training datasets, ensuring good performance on the corresponding validation sets, their prediction performance is evaluated on the test dataset as described in section 2.2.

\title{
5.2 Results and discussion
}

The test set prediction performance of the networks trained on the datasets with 1024 samples is shown in Figure 9 (top and middle). These results show that including only the climate locations that define the outer limits of the subspace (TrD-1) performs worse than the reference network trained on all climates (TrD-all). Although the input values of the other climates lie within the training subspace, the mapping learned by the network does not generalise well to these other climates. By including four additional climates from the Köppen-Geiger classification with average total rain load (TrD-2), the prediction error decreases, though the network is still not as accurate as the reference network trained on all climates (TrD-all). On the other hand, 
Postprint: Tijskens A., Janssen H., Roels S., 2020. The impact of a reduced training subspace on the prediction accuracy of neural networks for hygrothermal predictions. Journal of Building Simulation Performance 2021, 14(1)

https://doi.org/10.1080/19401493.2020.1832148

Figure 9 shows that the networks trained on the climates with maximum total wind-driven rain load (TrD-3) or on a representative selection of climates regarding wind-driven rain load ( $\operatorname{TrD}-4)$ have a similar prediction accuracy as the reference network trained on all climates (TrD-all). This implies that it is possible to train a network on a subset of climate locations and afterwards use it to predict accurately for other climates. 
Postprint: Tijskens A., Janssen H., Roels S., 2020. The impact of a reduced training subspace on the prediction accuracy of neural networks for hygrothermal predictions. Journal of Building Simulation Performance 2021, 14(1)

https://doi.org/10.1080/19401493.2020.1832148
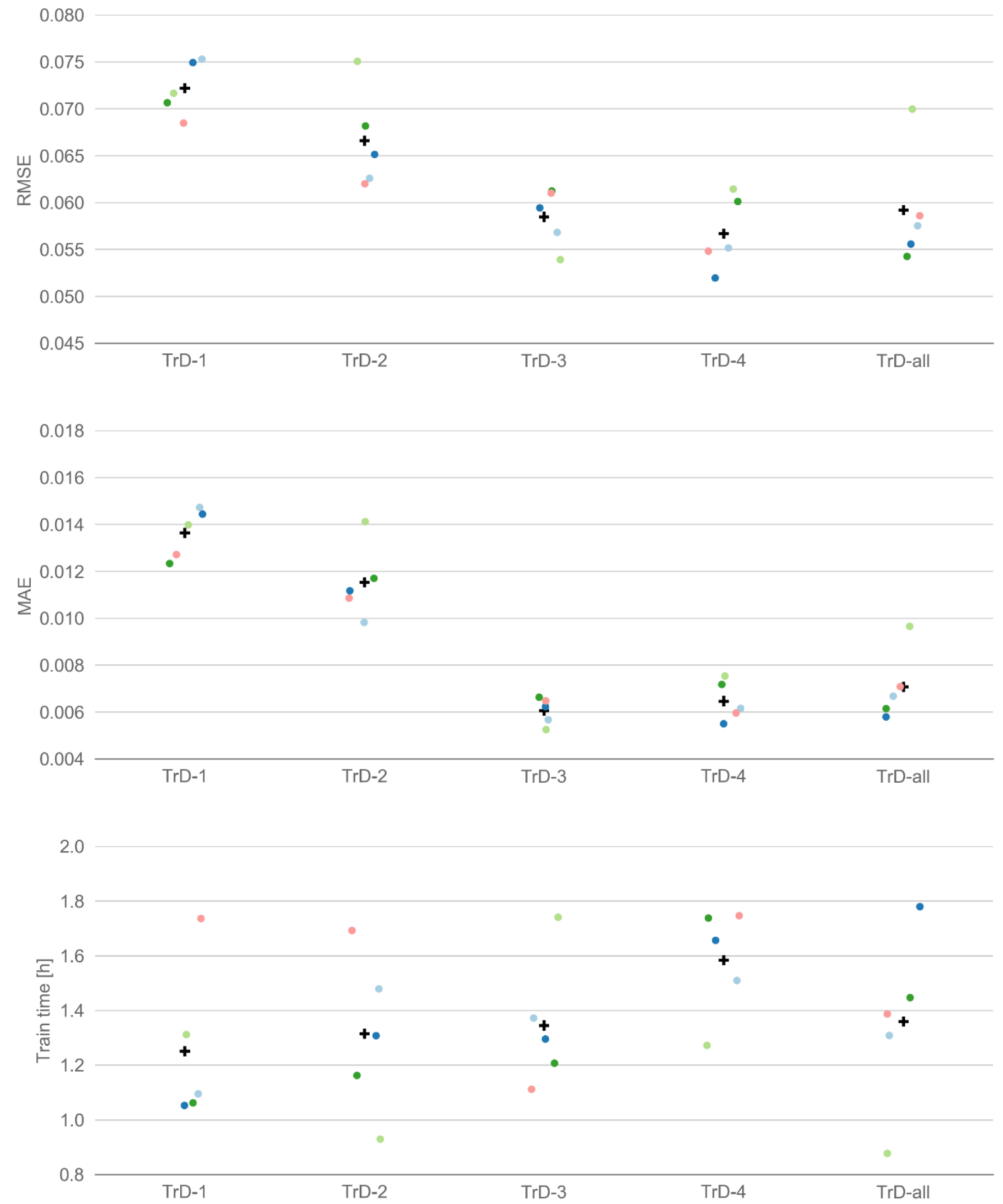

Figure 9: The prediction performance of the five networks, trained on the datasets with 1024 samples, and their mean values (black crosses) for the reference test set (top and middle) and the corresponding train time (bottom). 
Postprint: Tijskens A., Janssen H., Roels S., 2020. The impact of a reduced training subspace on the prediction accuracy of neural networks for hygrothermal predictions. Journal of Building Simulation Performance 2021, 14(1)

https://doi.org/10.1080/19401493.2020.1832148

Further analysis shows that, depending on the focus of the training dataset, the network predicts more accurately for some climates than others. Figure 10 shows the prediction performance averaged per climate location in function of the total wind-driven rain load over the whole 4-year simulation period, using the best performing networks per dataset from Figure 9. These results show that the low performance of TrD-1 and TrD-2 is mainly caused by high errors on climate locations with high total wind-driven rain load. This makes sense, since these climates were not represented in the training dataset. Moreover, TrD- 4 shows a profile very similar to the one of TrD-all, whereas TrD-3 shows a lower prediction error on high wind-driven rain load climate locations in comparison to TrD-all. This comes at the expense of some accuracy loss elsewhere, though; the low wind-driven rain load climates perform worse when training on $\operatorname{TrD}-3$ than when training on TrD-4 or TrD-all. A similar trend can be observed when using these hygrothermal predictions to estimate the damage risk. Figure 11 shows the performance indicators for predicting the decay of wooden beam ends, averaged per climate location and plotted in function of the total wind-driven rain load. Compared to the network trained on all climates, the wood decay for climate locations with high wind-driven rain load is clearly predicted more accurately using the TrD-3 network, but less accurately for climate locations with low winddriven rain load. The networks trained on TrD-4 and TrD-all again show a similar accuracy profile. Although not shown here, the same observations are found when prediction the moist freeze-thaw cycles and the mould growth index on the interior surface. Yet, the overall accuracy of the TrD-3, TrD-4 and TrD-all networks is similar, for both the hygrothermal predictions (Figure 9, top and middle) and the damage predictions (Figure 11, upper right of each panel). Therefore, all three methods to compose the training dataset lead to satisfying prediction results. 
Postprint: Tijskens A., Janssen H., Roels S., 2020. The impact of a reduced training subspace on the prediction accuracy of neural networks for hygrothermal predictions. Journal of Building Simulation Performance 2021, 14(1)

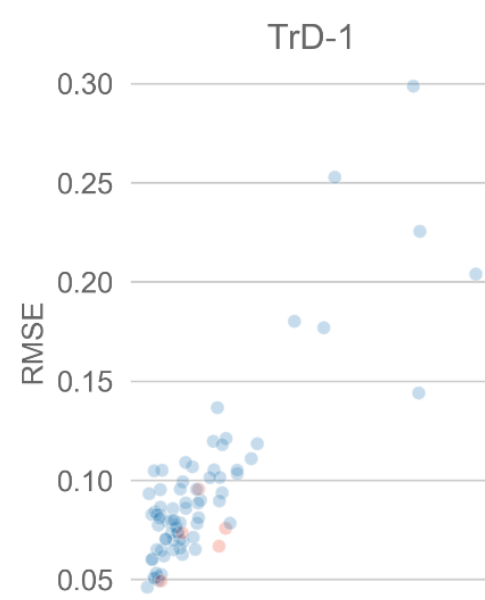

$0 \quad 500 \quad 1000$

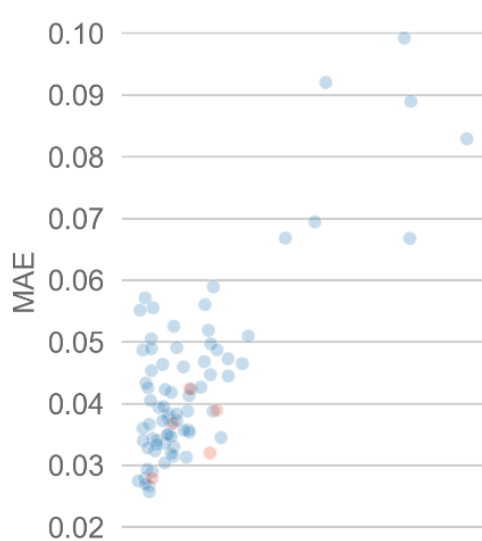

$0 \quad 500 \quad 1000$

Total wind-driven rain load $[\mathrm{mm}$
TrD-2

0.30

0.25

0.20

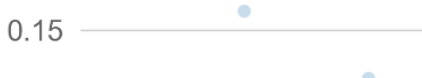

0.10

0.05
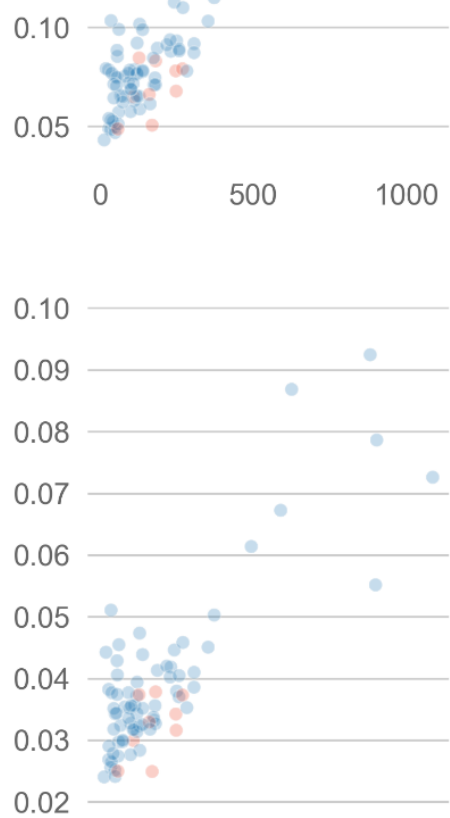

$0 \quad 500 \quad 1000$

Total wind-driven rain load [mm]
$\operatorname{TrD}-3$

0.30

0.25

0.20

0.15

0.10

0.05

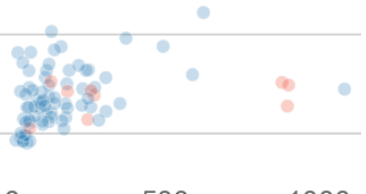

0.10

0.09

0.08

0.07

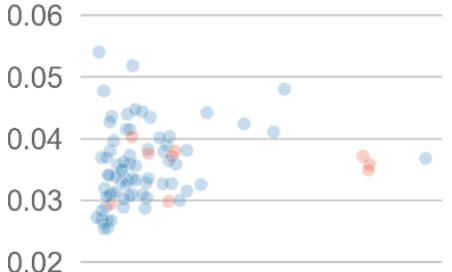

0.02

$\begin{array}{lll}0 & 500 \quad 1000\end{array}$

Total wind-driven rain load [mm]
TrD-4

0.30

0.25

0.20

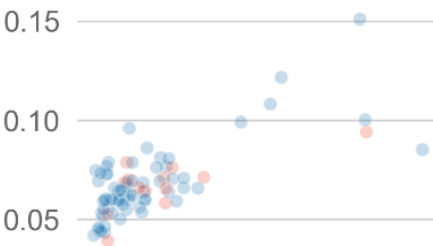

500

1000

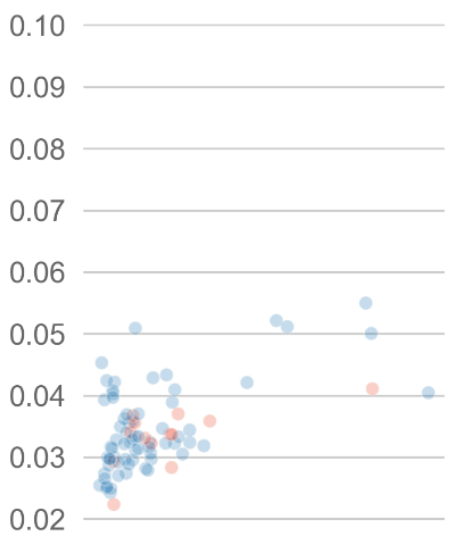

$\begin{array}{lll}0 & 500 \quad 1000\end{array}$ Total wind-driven rain load [mm]
TrD-all
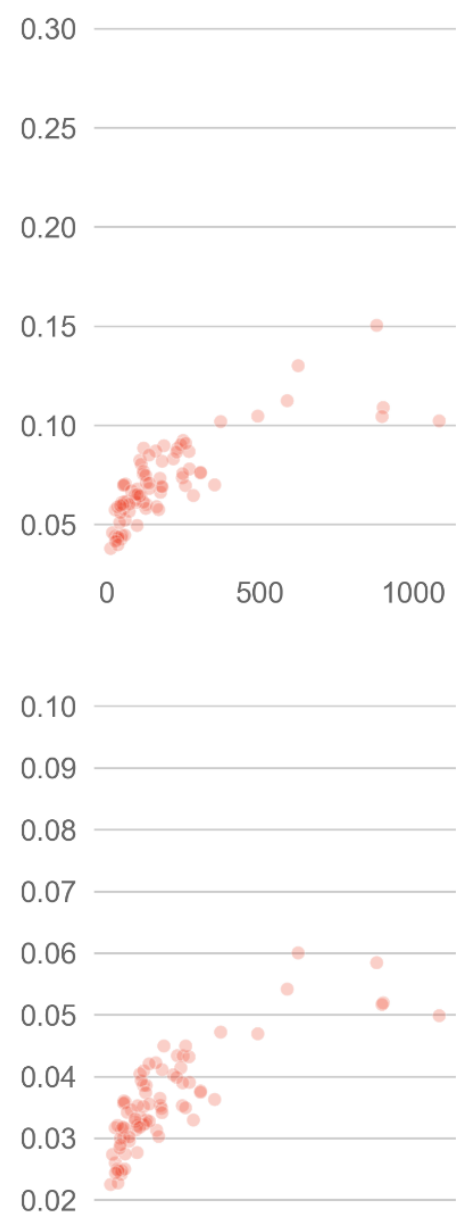

$\begin{array}{lll}0 & 500 \quad 1000\end{array}$ Total wind-driven rain load [mm] 
Postprint: Tijskens A., Janssen H., Roels S., 2020. The impact of a reduced training subspace on the prediction accuracy of neural networks for hygrothermal predictions. Journal of Building Simulation Performance 2021, 14(1)

https://doi.org/10.1080/19401493.2020.1832148

Figure 10: The networks' performance indicators, averaged per climate location, in function of the total wind-driven rain load during the four-year simulation period. The best performing networks, trained on datasets with 1024 samples, are used. To show whether there is a performance difference, the climate locations used during training are shown in red, while climate location not used during training are shown in blue. 
Postprint: Tijskens A., Janssen H., Roels S., 2020. The impact of a reduced training subspace on the prediction accuracy of neural networks for hygrothermal predictions. Journal of Building Simulation Performance 2021, 14(1)
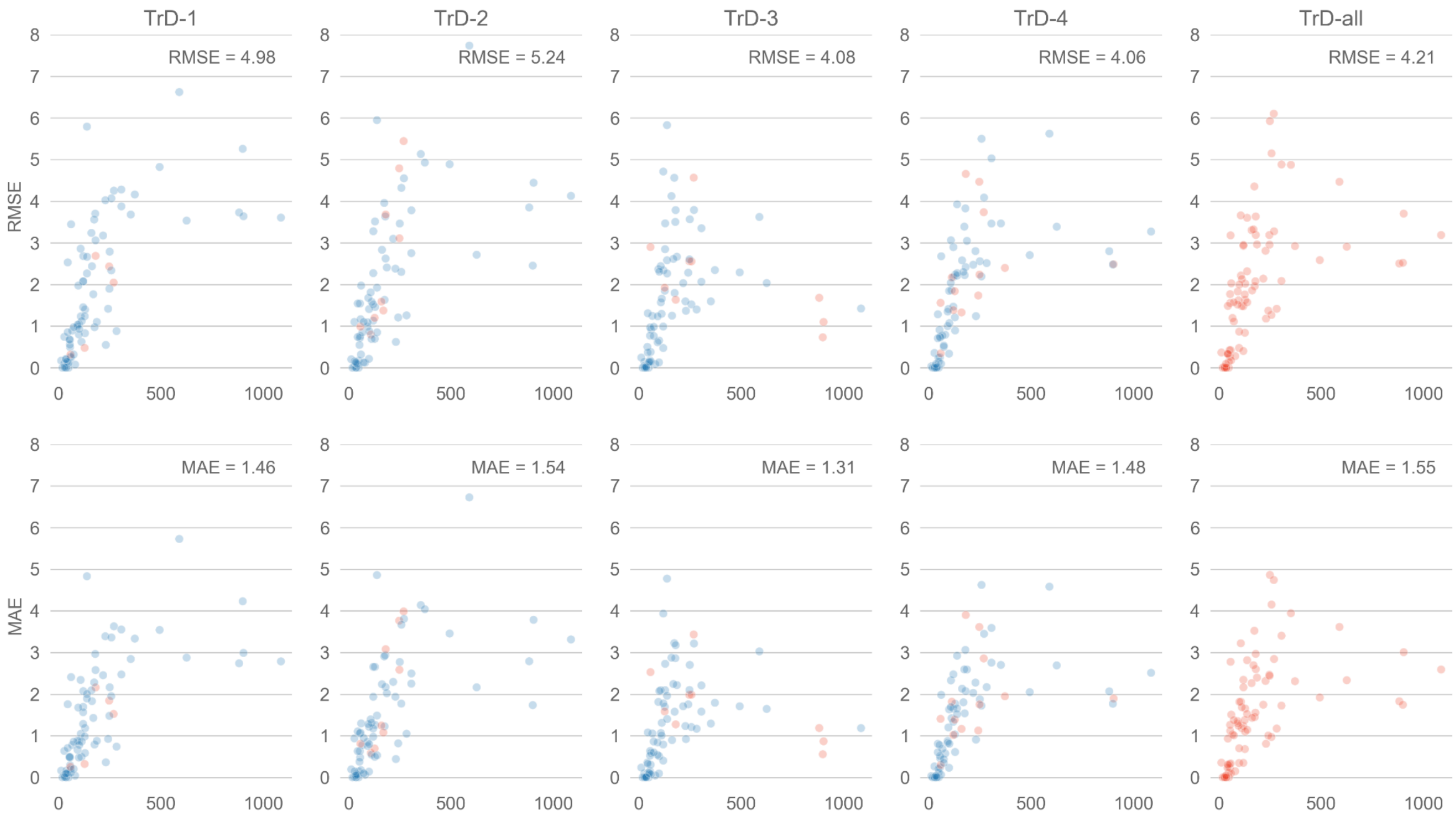

Total wind-driven rain load $[\mathrm{mm}] \quad$ Total wind-driven rain load [mm]
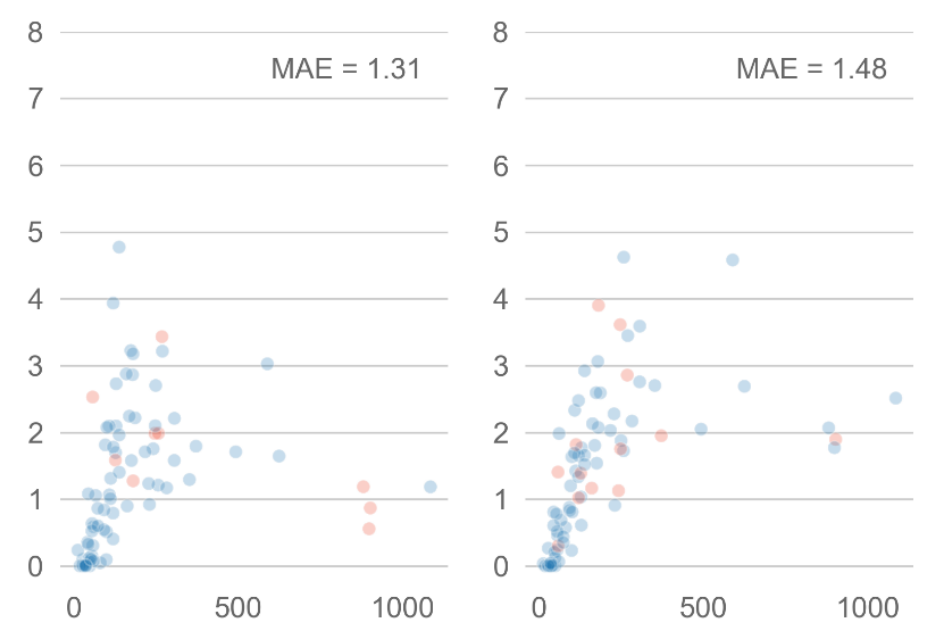

Total wind-driven rain load [mm] Total wind-driven rain load [mm]

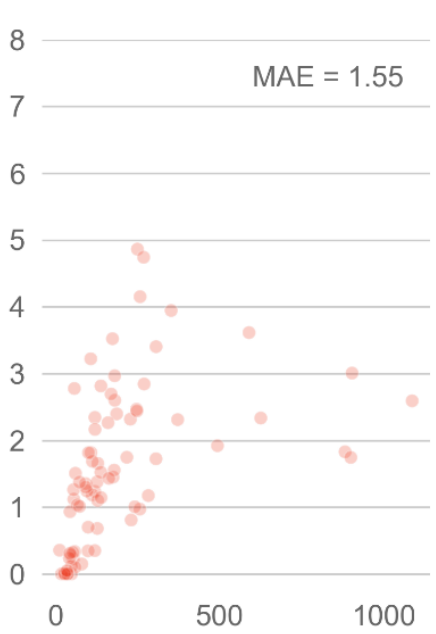

Total wind-driven rain load [mm] 
Postprint: Tijskens A., Janssen H., Roels S., 2020. The impact of a reduced training subspace on the prediction accuracy of neural networks for hygrothermal predictions. Journal of Building Simulation Performance 2021, 14(1)

Figure 11: The performance indicators for the decay of wooden beam ends, averaged per climate location, in function of the total wind-driven rain load during the four-year simulation period. For each dataset, the hygrothermal predictions by the best performing network are used. To show whether there is a performance difference, the climate locations used during training are shown in red, while climate location not used during training are shown in blue. 
Postprint: Tijskens A., Janssen H., Roels S., 2020. The impact of a reduced training subspace on the prediction accuracy of neural networks for hygrothermal predictions. Journal of Building Simulation Performance 2021, 14(1)

https://doi.org/10.1080/19401493.2020.1832148

To end, the impact of the number of training samples is analysed. Figure 12 shows the prediction performance of the networks in function of the number of samples. Clearly, reducing the number of samples leads to significant accuracy loss, for all datasets. Although not shown here, this accuracy loss was already observed for the validation dataset (which contains the same climate locations as the network was trained on), meaning that the network was not able to capture the variability of the uncertainty layer accurately, not even when there are fewer climate locations involved. This is in accordance with the observations from the first exercise, namely that enough samples are required to capture the variability of the uncertainty layer. As a result, reducing the number of climates in the training dataset does not allow using fewer training samples and thus does not lead to a lower training time.
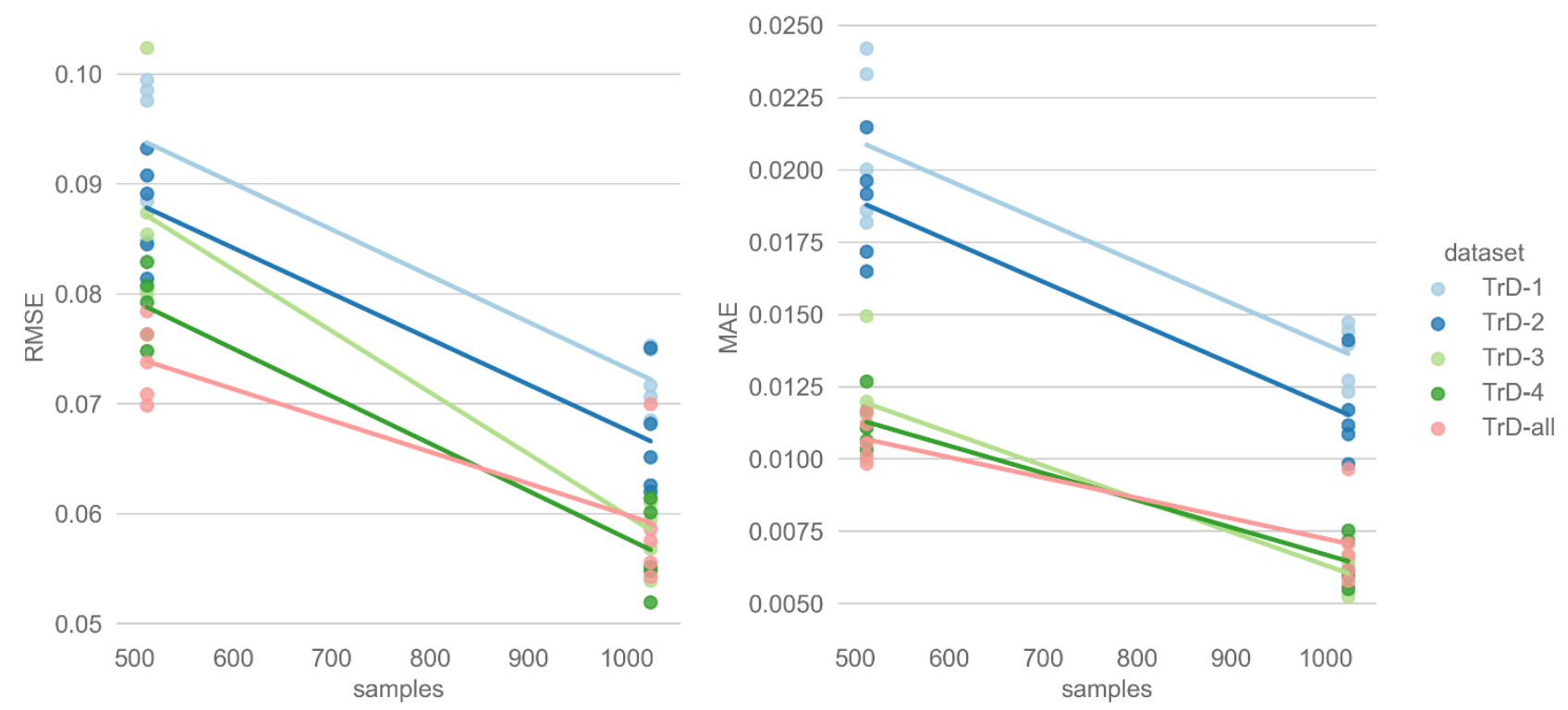

Figure 12: Network prediction performance in function of the number of training samples and dataset.

Hence, there seems to be little reason to exclude climate data from the training dataset, other than focusing on certain climatic aspects (i.e. low or high wind-driven rain load) and thus increasing the prediction performance for certain climate locations. Yet, the most important conclusion from this exercise is that it is possible to obtain high accuracy for climates the network was not trained on, as long as the new climates lie within the training subspace. Hence, when new climate data becomes available after training the network, it 
Postprint: Tijskens A., Janssen H., Roels S., 2020. The impact of a reduced training subspace on the prediction accuracy of neural networks for hygrothermal predictions. Journal of Building Simulation Performance 2021, 14(1)

https://doi.org/10.1080/19401493.2020.1832148

can be used to predict the hygrothermal performance. This way, time can be saved after all, as it is not necessary to develop a new neural network, training on the newly available data.

\section{Conclusion}

In this paper, convolutional neural networks are used to replace HAM models for building components, aiming to predict the hygrothermal time series (e.g. temperature, relative humidity, moisture content). Since neural networks do not extrapolate well, it is important to select the training data wisely so that the network can be used to predict for a wide variety of cases, while keeping training time as low as possible. In this paper, two exercises were conducted to investigate the impact of selecting a subspace for training on the prediction accuracy.

The first exercise investigates the possibility to train a single network on a limited number of wall types and subsequently accurately predict the hygrothermal performance of different wall geometries. The results showed that training on all wall types does not necessarily result in better prediction accuracy, and that the number of training samples plays a significant role. Training on a limited number of wall types but a larger amount of samples per wall type delivered a better performance, compared to training on all wall types and a smaller amount of samples per wall type. Since each wall type is subjected to the same samples for reliable comparison, training on fewer samples per wall type means that the network gets to see less data to capture the variability of the probabilistic parameters. Hence, when training time is an issue, it is worthwhile to reduce the amount of wall types while increasing the number of training samples per wall type.

The second exercise explores the possibility to train the network on a massive masonry wall and a limited set of exterior climates and subsequently accurately predict the hygrothermal performance in other climates. Results showed that this is indeed possible, as long as the training dataset is thoughtfully composed. Furthermore, results showed that by focusing on certain climatic aspects (i.e. low or high wind-driven rain load), the prediction performance increases for these climate locations. However, limiting the number of 
Postprint: Tijskens A., Janssen H., Roels S., 2020. The impact of a reduced training subspace on the prediction accuracy of neural networks for hygrothermal predictions. Journal of Building Simulation Performance 2021, 14(1)

https://doi.org/10.1080/19401493.2020.1832148

climate locations in the training dataset does not lead to a lower training time, since reducing the number of training samples also reduces the prediction accuracy, both on the validation set (which includes the same climates as the training dataset) and the test dataset (which includes all climates). Similar to the findings in the first exercise, the network needs enough samples to capture the variability of the probabilistic parameters, even when fewer climate locations are included in the training dataset. Taking all findings into account, limiting the number of climate locations in the training dataset appears to have limited or no advantage. Hence, the most important conclusion from this exercise is that it is possible to obtain high accuracy for climates the network was not trained on, as long as the new climates lie within the training subspace. This means that, when afterwards new climate data becomes available, it is not necessary to develop a new neural network and time is saved.

To conclude, the results of this research show that the application of a convolutional neural network replacing a hygrothermal simulation model can be very versatile, due to the interpolation possibilities. As stated in the introduction, a CNN could be used in probabilistic assessments for which standard HAM-models are often too time consuming. Another interesting example could be an online tool for decision making (e.g. which type of interior insulation is safe to use under specific conditions), where a CNN could be employed for fast, real-time simulations based on a limited amount of input from the user (e.g. architect or homeowner).

\section{Acknowledgement}

Funding: This research was funded by the European Union's Horizon 2020 research and innovation program under grant agreement No 637268.

Conflicts of Interest: The authors declare no conflict of interest. The funders had no role in the design of the study; in the collection, analyses, or interpretation of data; in the writing of the manuscript, or in the decision to publish the results. 
Postprint: Tijskens A., Janssen H., Roels S., 2020. The impact of a reduced training subspace on the prediction accuracy of neural networks for hygrothermal predictions. Journal of Building Simulation Performance 2021, 14(1)

https://doi.org/10.1080/19401493.2020.1832148

\section{References}

[1] L. Van Gelder, H. Janssen, S. Roels, Probabilistic design and analysis of building performances: Methodology and application example, Energy and Buildings. 79 (2014) 202-211. doi:10.1016/j.enbuild.2014.04.042.

[2] H. Janssen, S. Roels, L. Van Gelder, Annex 55 Reliability of Energy Efficient Building Retrofitting Probability Assessment of Performance \& Cost (RAP-RETRO), 2013.

[3] E. Vereecken, L. Van Gelder, H. Janssen, S. Roels, Interior insulation for wall retrofitting - A probabilistic analysis of energy savings and hygrothermal risks, Energy and Buildings. 89 (2015) 231244. doi:10.1016/j.enbuild.2014.12.031.

[4] E. Arumägi, M. Pihlak, T. Kalamees, Reliability of Interior Thermal Insulation as a Retrofit Measure in Historic Wooden Apartment Buildings in Cold Climate, Energy Procedia. 78 (2015) 871-876. doi:10.1016/j.egypro.2015.11.010.

[5] K. Gradeci, N. Labonnote, B. Time, J. Köhler, A proposed probabilistic-based design methodology for predicting mould occurrence in timber façades, in: World Conference on Timber Engineering, Vienna, Austria, 2016.

[6] J. Zhao, R. Plagge, A. Nicolai, J. Grunewald, Stochastic study of hygrothermal performance of a wall assembly - The influence of material properties and boundary coefficients, HVAC\&R Research. 9669 (2011) 37-41. doi:10.1080/10789669.2011.585421.

[7] H. Janssen, Monte-Carlo based uncertainty analysis: Sampling efficiency and sampling convergence, Reliability Engineering \& System Safety. 109 (2013) 123-132. doi:10.1016/j.ress.2012.08.003.

[8] L. Van Gelder, H. Janssen, S. Roels, Metamodelling in robust low-energy dwelling design, in: Central European Symposium on Building Physics, Vienna, Austria, 2013.

[9] D. Gossard, B. Lartigue, F. Thellier, Multi-objective optimization of a building envelope for thermal performance using genetic algorithms and artificial neural network, Energy \& Buildings. 67 (2013) 253-260. doi:10.1016/j.enbuild.2013.08.026.

[10] D. Bienvenido-Huertas, J. Moyano, C.E. Rodríguez-Jiménez, D. Marín, Applying an artificial neural network to assess thermal transmittance in walls by means of the thermometric method, Applied Energy. 233-234 (2019) 1-14. doi:10.1016/j.apenergy.2018.10.052.

[11] A. Tijskens, S. Roels, H. Janssen, Neural networks for metamodelling the hygrothermal behaviour of building components, Building and Environment. $162 \quad$ (2019) 106282. doi:10.1016/j.buildenv.2019.106282.

[12] A. Tijskens, H. Janssen, S. Roels, Optimising Convolutional Neural Networks to Predict the Hygrothermal Performance of Building Components, Energies. 12 (2019) 3966. doi:10.3390/en12203966.

[13] P.J. Haley, D. Soloway, Extrapolation limitations of multilayer feedforward neural networks, in: [Proceedings 1992] IJCNN International Joint Conference on Neural Networks, 1992: pp. 25-30 vol.4. doi:10.1109/IJCNN.1992.227294.

[14] E. Barnard, L.F.A. Wessels, Extrapolation and interpolation in neural network classifiers, IEEE Control Systems Magazine. 12 (1992) 50-53. doi:10.1109/37.158898.

[15] A. Šiljić Tomić, D. Antanasijević, M. Ristić, A. Perić-Grujić, V. Pocajt, A linear and non-linear polynomial neural network modeling of dissolved oxygen content in surface water: Inter- and extrapolation 
Postprint: Tijskens A., Janssen H., Roels S., 2020. The impact of a reduced training subspace on the prediction accuracy of neural networks for hygrothermal predictions. Journal of Building Simulation Performance 2021, 14(1)

https://doi.org/10.1080/19401493.2020.1832148

performance with inputs' significance analysis, Science of The Total Environment. 610-611 (2018) 1038-1046. doi:10.1016/J.SCITOTENV.2017.08.192.

[16] A. Tijskens, H. Janssen, S. Roels, Using convolutional neural networks for hygrothermal predictions to extrapolate to other external climates, in: Conference Proceedings of NSB, Tallinn, Estonia, 2020.

[17] K. He, X. Zhang, S. Ren, J. Sun, Deep Residual Learning for Image Recognition, in: IEEE Conference on Computer Vision and Pattern Recognition (CVPR), Boston, Massachusetts, 2015: pp. 107-117. http://arxiv.org/abs/1512.03385.

[18] E. Vereecken, S. Roels, Hygric performance of a massive masonry wall: How do the mortar joints influence the moisture flux?, Construction and Building Materials. 41 (2013) 697-707. doi:10.1016/j.conbuildmat.2012.12.024.

[19] European Commission, Climate for Culture: damage risk assessment, economic impact and mitigation strategies for sustainable preservation of cultural heritage in times of climate change, 2014. https://www.climateforculture.eu/.

[20] B. Blocken, J. Carmeliet, Spatial and temporal distribution of driving rain on a low-rise building, Wind and Structures, An International Journal. 5 (2002) 441-462. doi:10.12989/was.2002.5.5.441.

[21] European committee for Standardisation, EN 15026:2007 - Hygrothermal performance of building components and building elements - Assessment of moisture transfer by numerical simulation, 2007.

[22] M. Harrestrup, S. Svendsen, Internal insulation applied in heritage multi-storey buildings with wooden beams embedded in solid masonry brick façades, Building and Environment. 99 (2016) 59-72. doi:10.1016/j.buildenv.2016.01.019.

[23] X. Zhou, D. Derome, J. Carmeliet, Hygrothermal modeling and evaluation of freeze-thaw damage risk of masonry walls retrofitted with internal insulation, Building and Environment. (2017). doi:10.1016/j.buildenv.2017.08.001.

[24] V. Marincioni, G. Marra, H. Altamirano-medina, Development of predictive models for the probabilistic moisture risk assessment of internal wall insulation, Building and Environment. 137 (2018) 257-267. doi:10.1016/j.buildenv.2018.04.001.

[25] Delphin 5.8 [Computer software], (2014). https://www.bauklimatik-dresden.de/delphin/index.php.

[26] C. Feng, S. Roels, H. Janssen, Towards a more representative assessment of frost damage to porous building materials, Building and Environment. $164 \quad$ (2019) 106343. doi:10.1016/J.BUILDENV.2019.106343.

[27] H. Viitanen, T. Toratti, L. Makkonen, R. Peuhkuri, T. Ojanen, L. Ruokolainen, J. Räisänen, Towards modelling of decay risk of wooden materials, European Journal of Wood and Wood Products. 68 (2010) 303-313. doi:10.1007/s00107-010-0450-x.

[28] E. Vereecken, S. Roels, Wooden beam ends in combination with interior insulation: An experimental study on the impact of convective moisture transport, Building and Environment. 148 (2019) 524534. doi:10.1016/j.buildenv.2018.10.060.

[29] T. Ojanen, H. Viitanen, R. Peuhkuri, K. Lähdesmäki, J. Vinha, K. Salminen, Mold Growth Modeling of Building Structures Using Sensitivity Classes of Materials, in: Thermal Performance of the Exterior Envelopes of Buildings XI, Clearwater Beach, Florida, 2010: pp. 1-10. http://web.ornl.gov/sci/buildings/2012/2010 B11 papers/104_Ojanen.pdf.

[30] Robust Internal Thermal Insulation of Historic Buildings, (n.d.). https://www.ribuild.eu/ (accessed 
Postprint: Tijskens A., Janssen H., Roels S., 2020. The impact of a reduced training subspace on the prediction accuracy of neural networks for hygrothermal predictions. Journal of Building Simulation Performance 2021, 14(1)

https://doi.org/10.1080/19401493.2020.1832148

April 17, 2020).

[31] T. Hou, D. Nuyens, S. Roels, H. Janssen, Quasi-Monte Carlo based uncertainty analysis : sampling efficiency and error estimation, 2018.

[32] M. Eibl, R. Kilian, Climate For Culture - Collection of indoor and outdoor climate data from historic buildings throughout Europe for the determination of the overall range of indoor climate, 2011.

[33] H.E. Beck, N.E. Zimmermann, T.R. McVicar, N. Vergopolan, A. Berg, E.F. Wood, Present and future Köppen-Geiger climate classification maps at 1-km resolution, Scientific Data. 5 (2018) 180214. doi:10.1038/sdata.2018.214. 